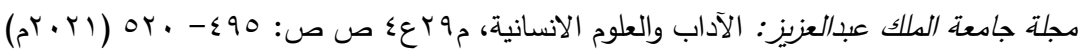 \\ DOI:10.4197/Art.29-4.18
}

\section{الابتكار في حقوق الملكيـة الأدبيّة والفنيسّة}

\author{
مها بنت مخلد العتيبي \\ طالبة ماجستير الأنظمة \\ قسم القانون الخاص - كلية الحقوق \\ جامعة الملك عبد العزيز - المملكة العربية السعودية
}

مستخلص. حقوق الملكية الفكرية تعدُّ جزءًا لا يتجزأ من حقوق الإنسان ومن أجل توفير حماية أمثل فقد سعت هذه الدراسة إلى بيان القيمة القانونية للابتكار في حقوق المؤلف؛ فتخصصت في مفهوم المؤلف ومصنفاته الفكرية؛ لتحدّد دور الابتكار فيها، وقد توصلت الدراسة إلى عدد من النتائج أهمها أنَّ الابتكار هو الثرط الوحيد لاستحقاق الحماية

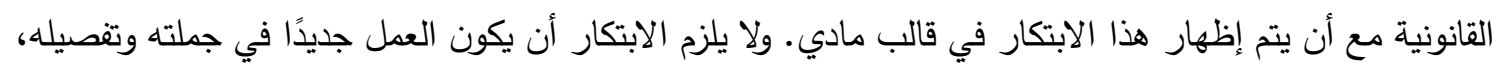
إنما المراد منه أن يظهر المصنف الفكري بطابع يبرز شخصية مؤلفه ومعبرًا عنها ومتسمًا بالجدة والتميز ، ويترتّب عن الاعتماد الكلي على هذا الشرط ألّا يؤخذ بعين الاعتبار مواصفات المصنف، وألّا يشترط القيام بأي إجراء شكلي لإني آخر لاستحقاق الحماية القانونيّة. الكلمات المفتاحية: الابتكار - حقوق المؤلف - المصنفات الفكرية - شروط الحماية القانونية.

جودة الحياة، لذلك كان لزامًا علينا مواصلة رعاية الاستثمار في البحث والتطوير واحتضان الابتكارات وحماية حقوق المبتكرين. وهذا ما تسعى إليه المملكة العربية السعودية إلى تحقيقه بحلول • r • ب؛ من كون
المـقــدمـة

إنَّ الابتكار قيمة مضافة لها وزنها وقيمتها في الاقتصاد الوطني والعالمي وفي المجتمعات كافة، وهو ما تسعى حقوق الملكية الفكرية إلى حمايته وتشجيعه. فلالبتكار دور فعّال في مواجهة التحديات وفي تحسين 
كما تهدف إلى بيان الشروط اللازمة لاستحقاق الحماية

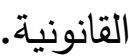
منهج الاراسة: حتّم هدف الدراسة استخدام المنهج التحليلي الاستتباطي العلمي، وذلك عبر تحليل النظام المختص بحماية حقوق المؤلف؛ للوقوف على شروط الحماية القانونية وإيضاح دور الابتكار . حدود الدراسة: ينحصر نطاق الدراسة تبعًا لهدفها

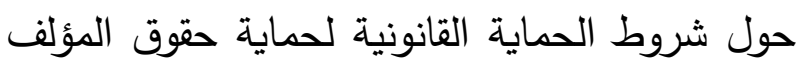

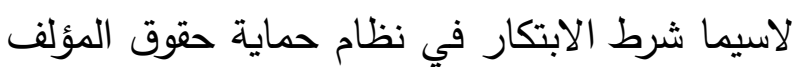

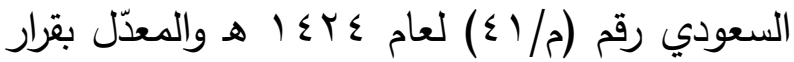

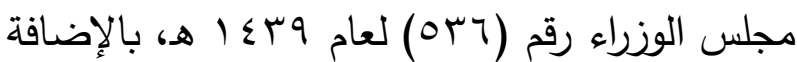
إلى اللائحة التنفيذية لذات النظام والمعدّلة بقرار مجلس إدارة الهيئة السعودية للملكية الفكرية لعام هـ ا ه.

ومما تقدّم طرحه فقد ارتأى للباحثة بناء خطة الدراسة

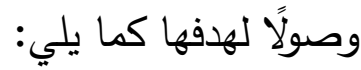
المبحث الأول: المدلول القانوني للمؤلف والمصنفات

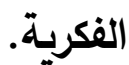
المطلب الأول: مفهوم المؤلف والمصنفات الفكرية.

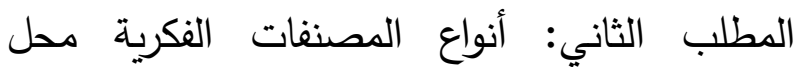

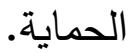

المبحث الثاني: طبيعة الابتكار في حقوق المؤلف وآثارها. المطلب الأول: معايير تحقّق الابتكار في المصنفات

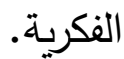

المملكة هي العمق العربي والإسلامي، القوة الاستثمارية الرائدة، ومحور ربط القارات الثلاث. مشكلة الدراسة: تتحور مشكلة الدراسة حول عنصر الابتكار في حقوق الملكية الأدبية والفنية، وعن لأن مضمونه وأثثر القانوني، الأمر الذي يدعونا إلى طرح التساؤل حول القيمة القانونية للابتكار في هذه المصنفات الفكرية؛ فما الدور الذي يحظى به الابتكار

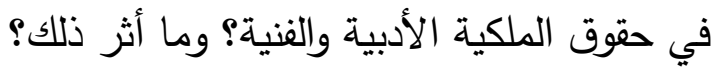

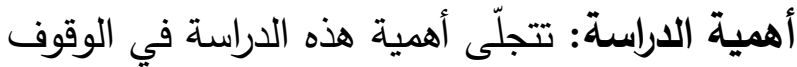
على دور الابتكار في حقوق المؤلف، وعن الآثار القانونية الناجمة عن ذلك. بالإضافة إلى فتح الآفاق البحثية حول الحماية القانونية لحقوق الملكية الفكرية وشروطها الموضوعية والثكلية، فضلًا عن إثراء المكتبة القانونية. تساؤلات الدراسة: تسعى هذه الدراسة إلى الإجابة عن

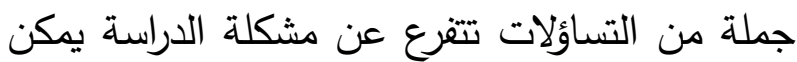
إجمالها في التساؤلات التالية: 1- ما المدلول القانوني لهفهوم المؤلف والمصنفات

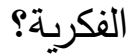
r- ما القيمة القانونية للابتكار كشرط لاكتساب الحماية القانونية على مصنفات حقوق المؤلف؟ ب- هل يعدُ أثر الابتكار كاشفًا لتلك الحقوق أم منشئًا لها! هدف الدراسة: تهدف هذه الدراسة بشكل أساسي إلى

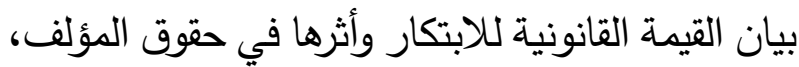


الذي تمَّ تفريخ التعبير فيهـ ‘ـ وهنا نلحظ ارتباط وصف المؤلف بالقيام بفعل جوهري هو الابتكار؛ فلا عبرة بالأعمال التي تأتي خاليةً من الابتكار؛ لفقدانها عنصر موضوعي يميّز حقوق الملكية الفكرية عن غيرها من الحقوق. وإنَّ الابتكار يأخذ أوصافًا عدة حسب الزاوية التي ينظر منها له؛ وذلك لاعتباره ظاهرة متعددة الأبعاد. لهذا نعرض للمقصود بمفهوم المؤلف

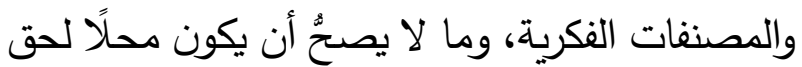
المؤلف. الفرع الأول: التعريف بالمؤلف وما لا يصح أن يكون محلًا لحقه.

إنَّ حقوق المؤلف هي الحقوق الاستئثارية المقرّرة لمصلحة المؤلفين ؛؛ كمكافأة لهم تمكّنهم من الانتفاع بأعمالهم بما لا يتعارض مع حقوقهم الأدبية ودون تعرض من الآخرين ْْ وهي تغطي جملة من الأعمال الإبداعية `؛ كالمؤلفات، الصور والمواد الصوتية، والبرمجيات الحاسوبية والتصاميم المعمارية، وقد أوردها المنظّم السعودي على سبيل المثال لا الحصر ؛ لاستيعاب مبتكرات الأعمال مستقبلًا. وقبل الشروع في التعريف بالمؤلف ومصنفاته الفكرية لدراسة قيمة الابتكار القانونية فيها، فإننا نعرض إلى مفهوم وثيق الصلة بحقوق المؤلف وهو "الحقوق

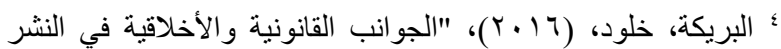

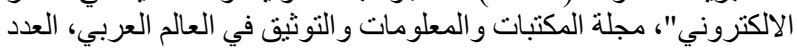

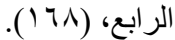

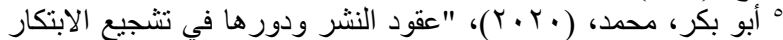

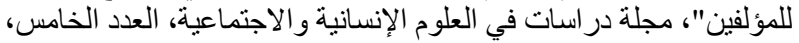
(0.0-0. $(0)$

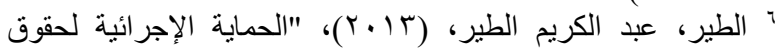

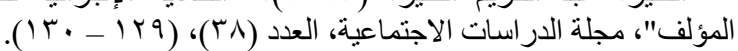

المطلب الثاني: الآثار المترتبة عن الاعتماد الكلي

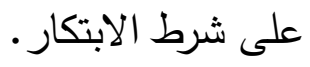
المبحث الأول: المدلول القانوني للمؤلف والمصنفات الفكرية. إنَّ حقوق المؤلف تطلق على طائفة واسعة من الأعمال المبتكرة؛ ويأتي اصطلاح هذه الأعمال المبتكرة بحقوق المؤلف تبعًا لمعيار الذاتية الذي يحكمها، فشخصية المؤلف وطابعه الخاص تلعب دورًا مهمًا في هذه الحقوق '. وهنا نود الإشارة إلى أنَّ ظهور شخصية المؤلف في مصنفه المبتكر هو ما يستدعي الحماية القانونية لا شخصه؛ فالأشخاص متساوون أمام القانون تبعًا لخصيصة العمومية والتجريد التي تميّز القواعد القانونية، وإنَّ استحقاق الحماية يكون بظهور شخصية المؤلف في مصنف يتسم بالابتكار ‘ُ. ووصولًا لهدف الدراسة؛ فإننا نعرض لهول هذا المبحث على مطلبين هما: مفهوم المؤلف والمصنفات الفكرية، وأنواع المصنفات الفكرية محل الحماية. المطلب الأول: مفهوم المؤلف والمصنفات الفكرية. يعرّف المنظّم السعودي المؤلف بأنّه كل مبدع ابتكر بجهده مصنف أدبي أو فني أو علمي كالأديب أو الشاعر أو الرسام وغيرهم، ويكون ذلك وفقًا للقالب

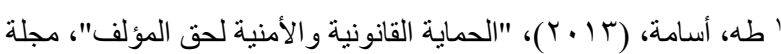

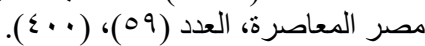

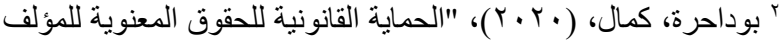

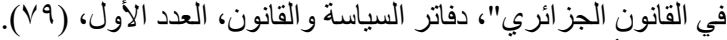

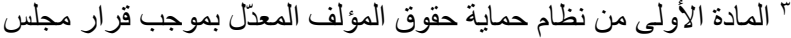

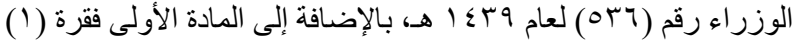

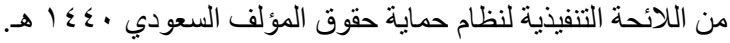


اللائحة التنفيذية لنظام حماية حقوق المؤلف بأنَّه: " كل مبدع ابتكر بجهده مصنف أدبي أو فني أو علمي

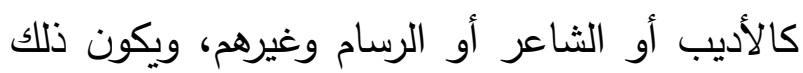

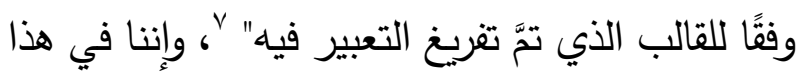
المطلب نعرض إلى مفهوم المؤلف لارتباطه بمصنفه

الفكري الذي هو محل الحماية القانونية. أولًا: التعريف بالمؤلف. لون.

عند إطلاق مصطلح "المؤلف" يتبادر إلى الأذهان أنَّ المؤلف هو من يكتب كتابًا وفي هذا القول قصورًا،

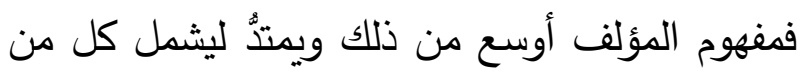
ينتج إنتاجًا ذهنيًا بصرف النظر عن نوعه؛ وهذا باستثناء المخترعين ومبتكري العلامات التجارية لهنية وغيرهم الذين يخضعون لأحكام خاصة.

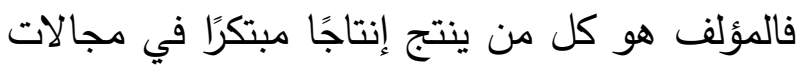
الثقافة المختلفة ويظهر في نتاجه طابعه المميّز وبصمته الخاصة ويقوم بنشر عمله منسوبًا إليه،

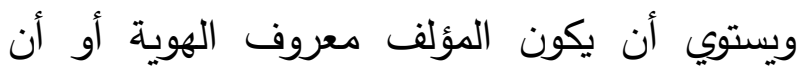

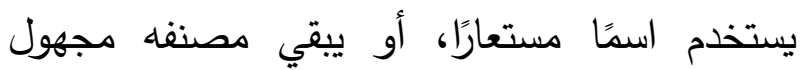
المؤلف ^.

• المادة الأولى فقرة (1) من اللائحة التنفيذية لنظام حماية حقوق المؤلف هـ $1 \leq$ ' المادة الأولى نظام حماية حقوق المؤلف المعدّل بموجب قرار مجلس

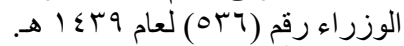

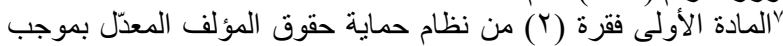

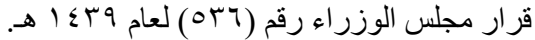

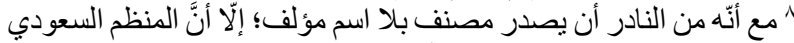

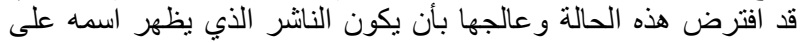

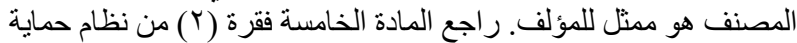

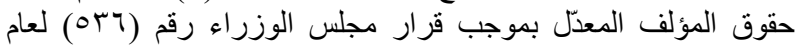

المجاورة لحق المؤلف"، كما نميّز بين مصطلحين

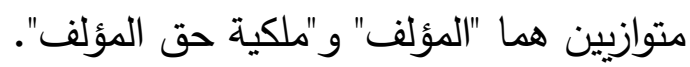
فالحقوق المجاورة لحق المؤلف هي المصالح القانونية لبعض الأشخاص التي تسمح بدورها في إتاحة المصنف للجمهور وتسهم في تداوله ونشره؛ فهي على بلى لإنى قدر من الإبداع والمهارات التقنية وغيرها التي تبرّر لها

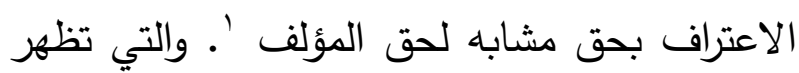
في أوساط فنانو الأداء كالممثلين في أدائهم، ومنتجو التسجيلات الصوتية على تعدّد وتطوّر أدواتهم المستخدمة في التسجيل، بالإضافة إلى هيئات الإذاعة

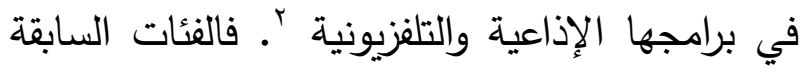
تعرف بالحقوق ذات الصلة بحقوق المؤلف أو الحقوق المجاورة ‘، وتتمثّل غاية منح المنظّم الحماية القانونية لهذه الفئات في تقدير جهودهم لمساعدة المبتكرين

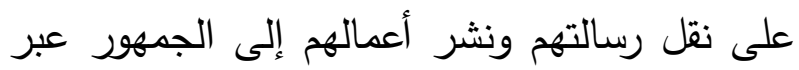
الحقوق المجاورة ؛. أمَّا حق ملكية المؤلف فهي "مجموعة المصالح

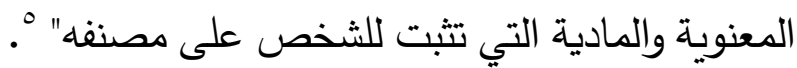

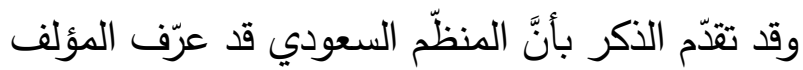

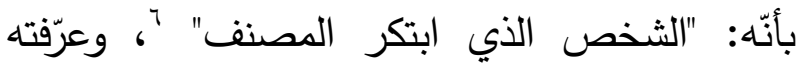

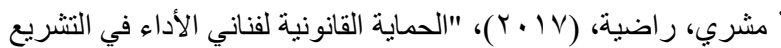

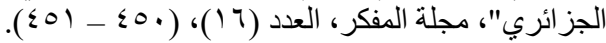

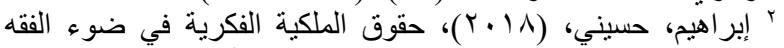
الإسلامي ونظام حقوق المؤلف السعودي، الطبعة الأولى، (الطائف: بدون

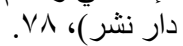

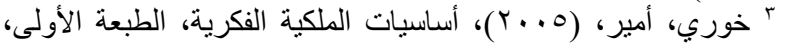

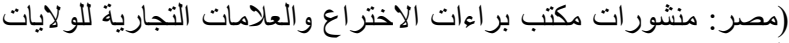

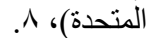

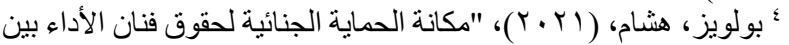

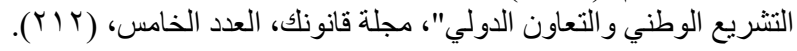


أصل التصرف فيه عائدًا إلى الاتفاق بينهم ويحتفظ كل منهم بحقه في رد الاعتداء عن نصيبه من قبل الغير أو حتى الشركاء ؛، ويختلف هذا المصنف عن سابقه بإمكانية استغلال كل مؤلف لنصيبه بشكل مستقل شريطة ألّا يتعسف وألّا يضر بحقوق شركائه الآخرينْ ج- المصنف الجماعي: وهو ما اشترك في إنتاجه أكثر من شخص بتوجيه من شخصية اعتبارية أو معنوية تتكفل بنشر المصنف تحت إدارتها وباسمها، وفي هذا النوع من المصنفات يكون للشخص المعنوي لهني الذي وجّه بإخراج المصنف حق مباشرة سلطات

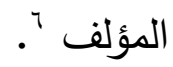

د- المصنف المشتق: المصنفات المشتقة هي المصنفات التي تكون مستمدة من مصنفات أخرى؛ لكنها تتميز عنها في الشكل أو المضمون كالترجمة والتلخيص شريطة أن تكون مبتكرة `، وبموجب النظام

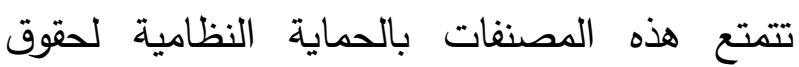
المؤلف ولا يؤثر ذلك على حماية المصنفات

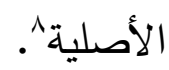

ثانيَّا: ما لا يصحُّ أن يكون محلًا لحق المؤلف.

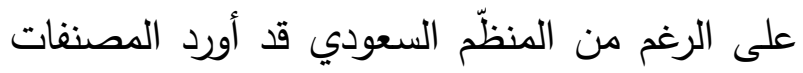

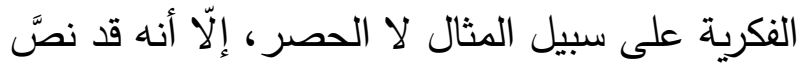

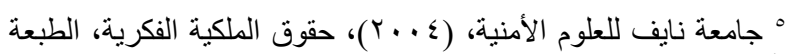

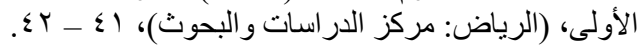

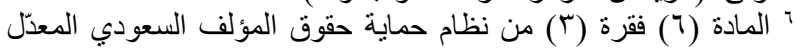

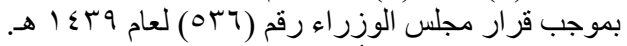

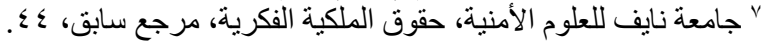

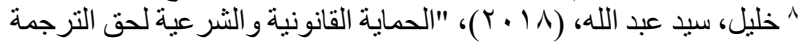

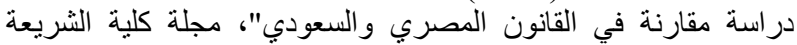

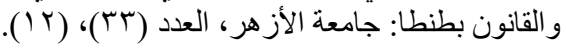

فالمؤلف مفهوم بوسعه أن يستوعب طائفة المبدعين

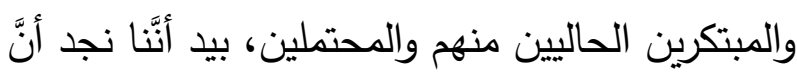
أنماط المؤلفين تبعًا لارتباطهم بمصنفاتهم الفكرية تتنوع وفقًا لما يلي: أ- المصنف الذي يؤلفه شخص واحد: هو أكثر المصنفات شيوعًا فغالبًا ما يقوم شخص واحد بإنتاج المصنف وينسب إلى مؤلفه عن طريق ذكر اسمه لهاه

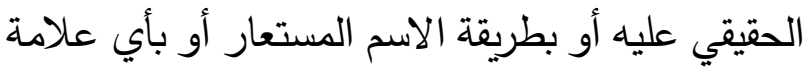
تقطع أواصر الثك في التعرف على حقيقة المؤلف '. ب- المصنف المشترك: وهو ما اشترك في إنتاجه أكثر من شخص وتضمن اشتراكهم مساهمة كل فرد منهم في ابتكارية المصنف مع اشتراك فكرهم واتجاه جهودهم إلى إخراج هذا المصنف وهي على نوعين، مصنف المنف مشترك غير قابل للانقسام ومصنف مشترك قابل للانقسام ‘؛ فالمصنف غير عير القابل للانقسام لا يمكن فصل نصيب كل مؤلف على حدا ويكون عند فرض

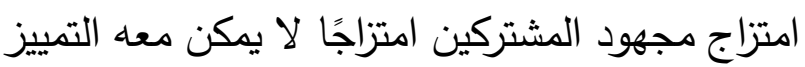

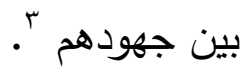
أمًا المصنف المشترك القابل للانقسام؛ فهو المصنف الذي يشترك في تأليفه أكثر من شخص مع إمكانية التمييز بين أنصبتهم في العمل، وفي هذه الحالة يكون

' المادة (0) فقرة (1) من نظام حماية حقوق المؤلف السعودي المعدّل

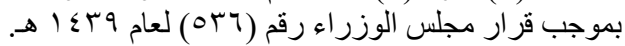

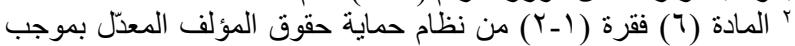

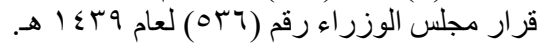

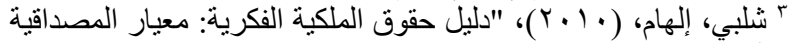

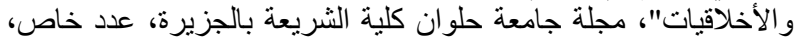

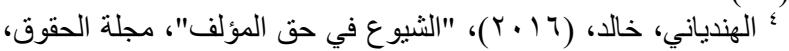

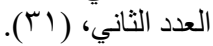


بل كافة أوجه النشاط الإنساني وقد يؤدي ذلك إلى الإخلال بجودة التعليم والبحث والتطوير . وكذلك الحال بالنسبة إلى الأعمال المتمثلة في أساليب العمل والإجراءات السابق بيانها؛ فنجد في إضفاء الصبغة القانونية عليها صعوبة بالغة في الناحية

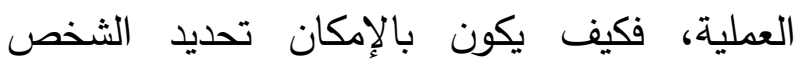
المستحق لأن يكون مؤلفًا لهذه الأعمال، وأن يستأثر بحقوق المؤلف عليها؟ أمّا بالنسبة إلى الفئة المتمثلة في الأخبار والنشرات فقد أحسن المنظّم السعودي في استدراك الفقرة بعبارة "ذات التهات الصبغة الإخبارية"، وذلك لأن ما يتم لغرض الإخبار

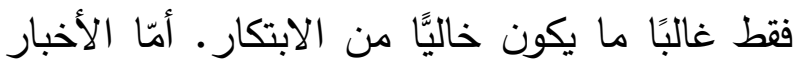
والنشرات التي تتسم بطابع ابتكاري؛ فلا ترى الباحثة ما يمنع من أن تكون محلًا لحق المؤلف، وذلك لأنها ليست المقصودة من استثناء النظام لها إنما جاء الاستثناء لتلك الاعمال الخالية من الطابع الابتكاري.

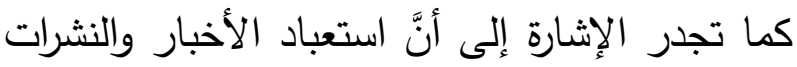

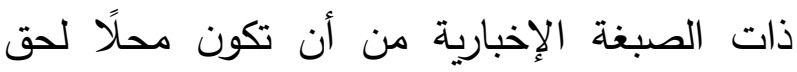

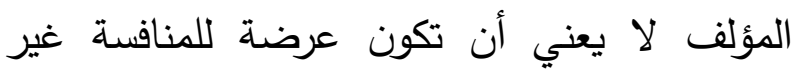
المشروعة؛ إنما تحمى وفق أنظمة خاصة واستبعادها كان لغرض عدم اتساقها مع مفهوم حقوق المؤلف

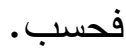
فالمؤلف لم ينشئ مصنفه من العدم متفردًا إنما لابد أن يكون للبيئة التي أحاطت به ولمن سبقوه في المجال
بصريح النظام على عدد من الأعمال التي لا تصحُّ أن تكون محلًا لحق المؤلف؛ فهي مستبعدة بقوة النظام من أن تكون محلًا لذلك. وهذه الأعمال تتمثّل في قرارات الهيئات الإدارية، الاتفاقيات والمعاهدات الدوليّة، الأحكام القضائية والأنظمة القانونية، وتشمل كذلك ترجمات هذهات النصوص، بالإضافة إلى ما تقوم بنشره المجلات والصحف، أو ما تذيعه محطات الإذاعة من أحداث أو إخباريات تتسم بالنمط الخبري، وكذلك ما يصدر

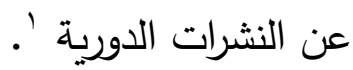
كذلك لا يصحُّ أن تكون أساليب العمل أو إجراءاتها،

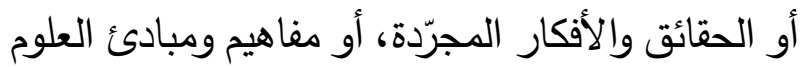

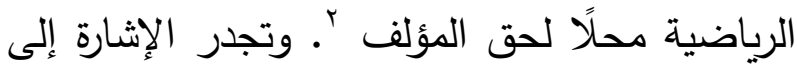
أنَّ هذه الأعمال قد وردت على سبيل الحصر ، وكل ما عدا ذلك مما قد استوفى شرط الابتكار وتم إخراجه

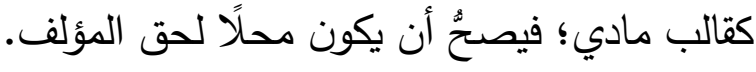
وترى الباحثة أنَّ غرض استثناء المنظّم السعودي للأعمال السابقة من أن تكون محلًا لحق المؤلف؛ هو ألّا تكون هذه الأعمال التي جاءت من أنساء من أجل الصالح

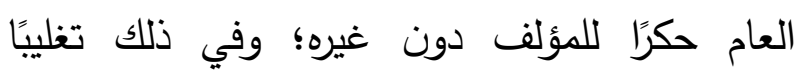
للمصلحة العامة عن مصلحة المؤلف الخاصة وذلك في الفئة الأولى المتمثلة في الوثائق الرسمية؛ ففي

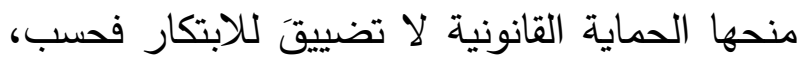
' المادة الرابعة نظام حماية حقوق المؤلف المعدّل بموجب قرار مجلس

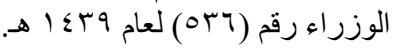


أمّا الاقتباسات فهي الاستشهاد بفقرات قصيرة من مصنف محمي نظامًا؛ ليصبح بهذا مشروعًا نقلُ فقرات معينة من مصنف محمي لغرض توضيح فكرة أو مئري إضفاء القوة عليها أو حتى لنقد ما جاء فيها. ويشترط لمشروعية الاقتباس: أن يكون المصنف في متناول الجمهور بصورة مشروعة، وأن يكون الاقتباس بالقدر الذي تبره الغاية المرجوة منه، كما يجب أن يذكر المصدر المقتبس منه وأن يذكر اسم مؤلفه ؛. وشأن استخدام المصنفات لأغراض العملية التعليمية فيعدُّ هذا قيدًا دوليَّا ْيردُ على كافة المصنفات المحمية بموجب حقوق المؤلف بما يمكّن المعنيين من طلاب وأساتذة؛ بل ويشمل إجراءات التدريب المهني باعتبارها أحد أوجه الأغراض التعليمية. ويشترط للاستفادة من هذا القيد على حقوق المؤلف لتحقيق أهدافه أن يكون استخدام المصنف لغرض تعليمي بحت، وأن يكون هذا الاستخدام في الحدود التي يبررها الهدف المنشود

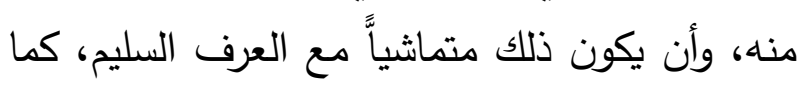
يشترط أن يذكر اسم المؤلف واسم المصنف، ويدخل تحت هذا القيد استنساخ المصنفات من قبل المكتبات العامة أو مراكز التوثيق غير التجارية أو المؤسسات

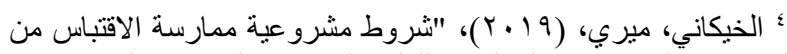
المصنفات الفكرية"، مجلة الكوفة للعلوم القانونية و السياسية، العدد (1 (؟))، (OV_Or)

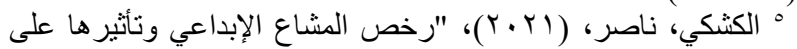
حقوق الملكية الفكرية"، المجلة العلمية للمكتبات و الوثائق و المعلومات،

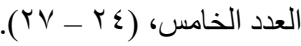

دور في ابتكار المصنف؛ لهذا يعتبر البعض أنَّ القيود والاستثناءات الواردة على حق المؤلف تأتي من منطلق الموازنة بين ما استعان به المؤلف لإنتاج مصنفه وبين ما يحتاجه المؤلفين المحتملين لإنتاج مصنفاتهم ' مصنه وهذه الاستثناءات هي ما تقدّم بيانه فيما لا يصـُّ أن يكون محلًا لحق المؤلف وللاعتبارات السابق بيانها، أمَّا القيود الواردة على حق المؤلف فهي حالات خاصة

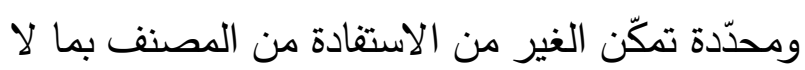
يتعارض مع حقوق المؤلف الأدبية؛ وهي تراخيص الترجمة والاستنساخ، الاقتباسات، واستخدام

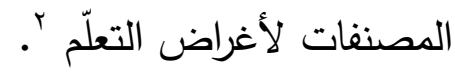
فتراخيص الترجمة والاستساخ التي تمنح على المصنفات هي قيود تضعها التشريعات الوطنية والاتفاقيات الدولية على حقوق المؤلف، بالإضافة إلى الاستعمال الحر أو الانتفاع المشروع للمصنف المحمي؛ فيكون ذلك في حالات خاصة ومع مراعاة شروط خاصة بكيفية الاستعمال ومداه، ويشترط في هذه الاستعمالات ألّا تكون لهدف تجاري وألّا تؤثر

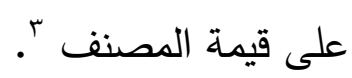

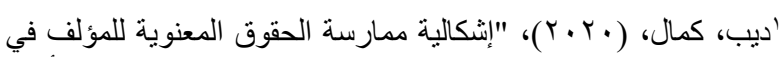

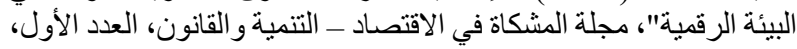

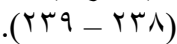

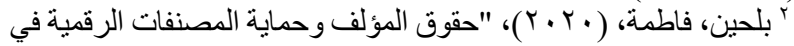

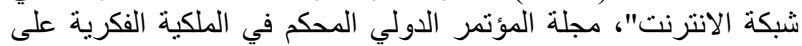

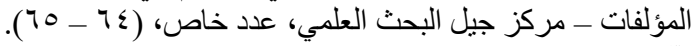

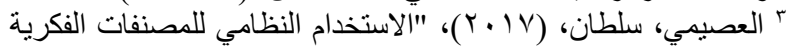

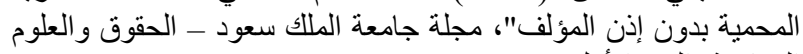

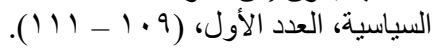




\section{الفرع الأول: المصنفات الأصلية.}

المصنفات الأصلية هي المصنفات التي أخرجها مؤلفوها بصورة مباشرة دون أن تقتبس من المصنفات السابقة عنها، وتسمى بالمصنفات الأصلية لأنها وليدة

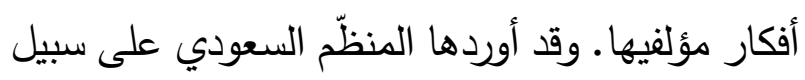
المثال لا الحصر ؛ لأنه لا يمكن حصرها فهي تتجدد التها.

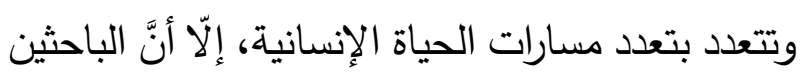
قد درجوا على تصنيفها إلى فئات لغرض تسهيل الدراسة: هي المصنفات الأدبية والعلمية، المصنفات الفنية '.

أ- المصنفات الأدبية والعلمية: إنَّ الإنتاج الأدبي

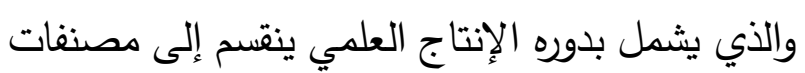

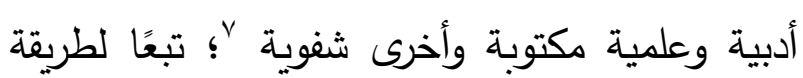

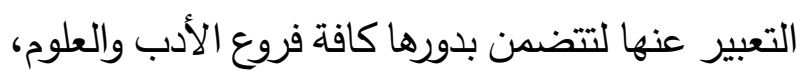
وكذلك الحال بالنسبة للمصنفات المكتوبة في كل بلورهات مجالات الأدب والعلم التي تصل إلى الجمهور عن بالنه

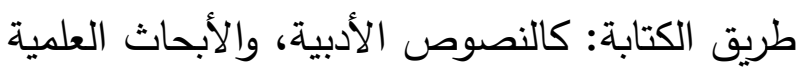
أو التقنية، والروايات والقصص والقصائد الثعرية،

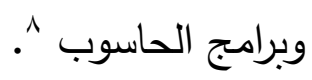
ولا فرق في الحماية القانونية بين المصنفات الخيالية

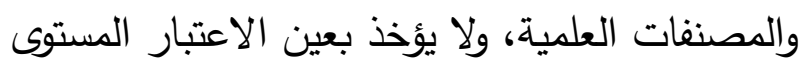

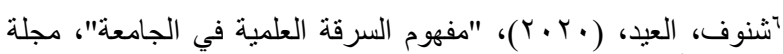

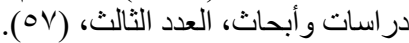

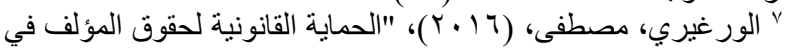

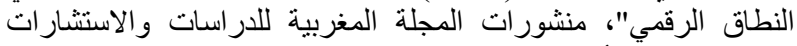

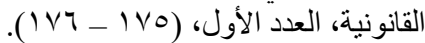

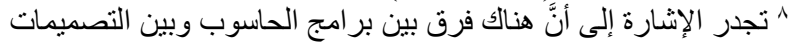

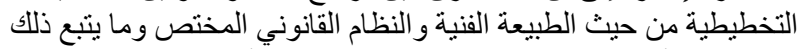

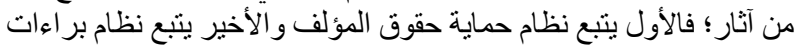
الاختراع في التنظيم المختص بالتصميمات التخطيطية للارارات المتكاملة.
العلمية أو المعاهد للمصنف المحمي شريطة ألّا يكون ذذلك للاستغلال التجاري '. كما ظهر في القانون ما يعرف بأحكام النسخة

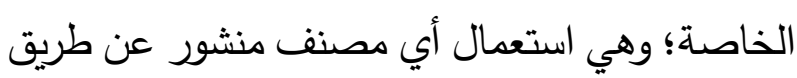
إعداد نسخة واحدة منه لاستعماله لغرض شخصي الغئي

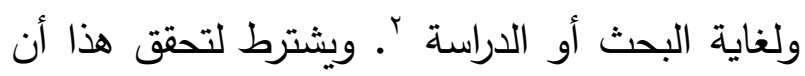
تقتصر النسخة الخاصة على الاستعمال الفردي دون

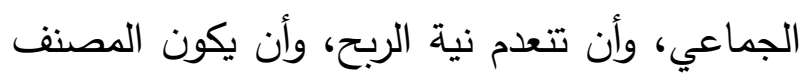

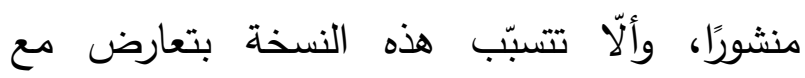

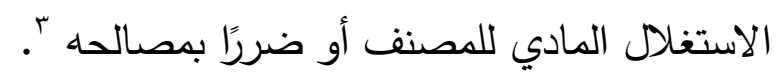
المطلب الثاني: المصنفات الفكرية وأنواعها. يعرّف المنظّم السعودي المصنّف بأنّه: "أي عمل

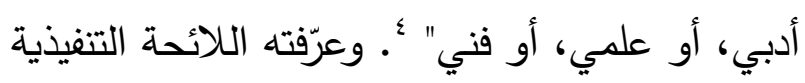
بأنّه "الإنتاج الأدبي أو العلمي أو الفني المبتكر مهما

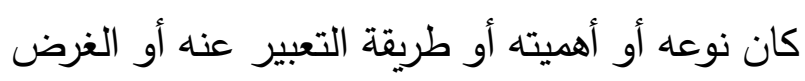
من تأليفه" •. وإننا بهذا الصدد نعرض إلى إلى طائفتين رئيستين من المصنفات الفكرية هما المصنفات الأصلية والمصنفات المشتقة؛ نظرًا لأن دور الابتكار

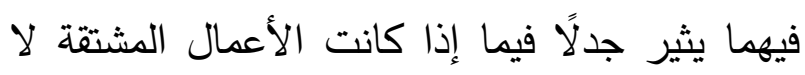
تحقّق الابتكار كشرط موضوعي يميّز حقوق المؤلف.

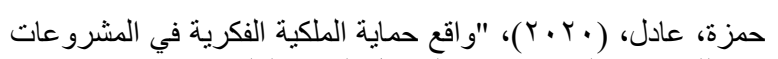

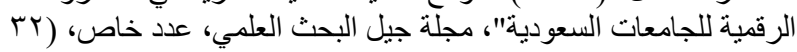

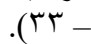

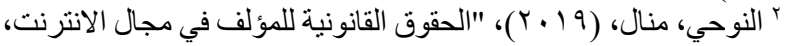

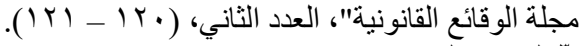

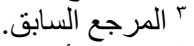

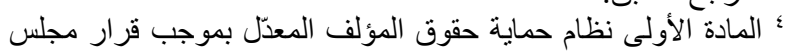

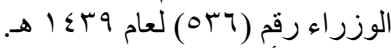

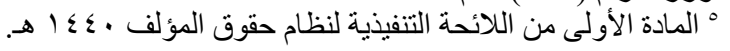


وكذلك الحال بالنسبة إلى الجغرافيا أو العلوم فنجد فيها أعمالًا يصحُ اعتبارها مصنفات فنية: كالرسوم البيانية

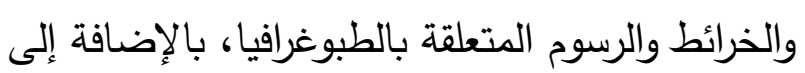

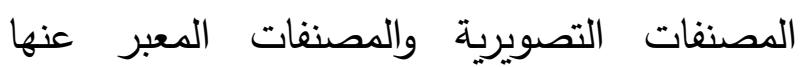
بأسلوب يماثل التصوير ْـاته الفرع الثاني: المصنفات المشتقة. تعرّف المصنفات المشتقة بأنها الأعمال التي لا تأخذ التذات من المصنف الأصلي سوى بعض من عناصره

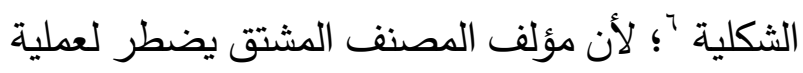
ابتكار إنتاجه المشتق عبر تحويل المصنف الأصلي

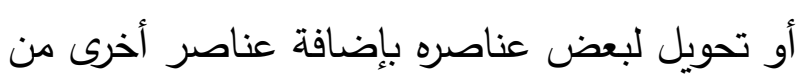

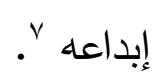

ومع هذا فلا يمكن غالبًا التثريق بسهولة بين المصنف الأصلي والمصنف المشتق منه؛ كأعمال الترجمة

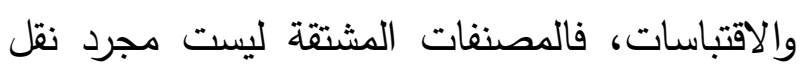

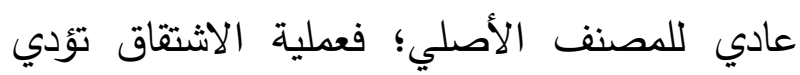
بالضرورة إلى نقل مبتكر للمصنف الأصلي وإلى الإئى تداوله ^. إلّا أنَّ حماية المصنفات المشتقة أدّت إلى وجود علاقات وحقوق متنافسة بين المؤلفين، لأن الابتكار

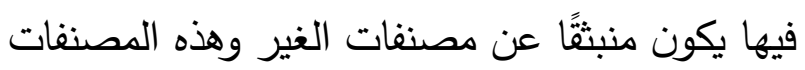

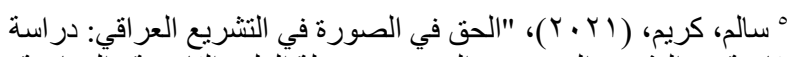

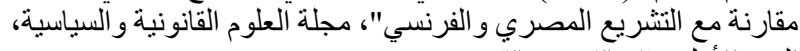

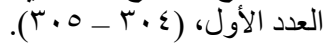

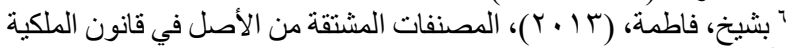

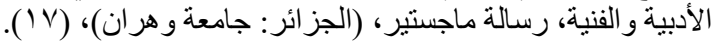

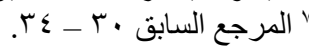

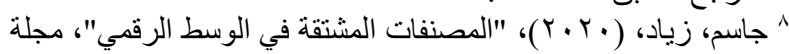

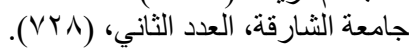

الثقافي للمؤلف، كما لا تمييز بين المصنفات التقليدية

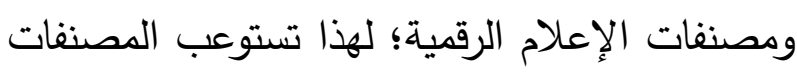

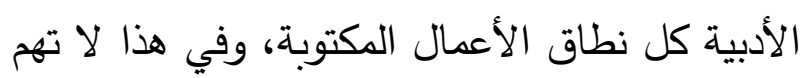

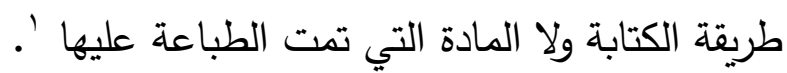

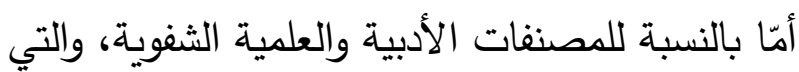

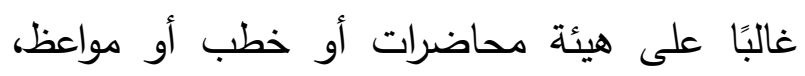

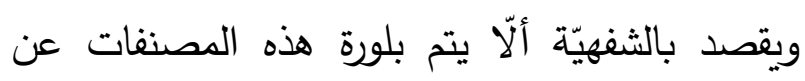
طريق الكتابة؛ إنما عن طريق الصوت؛ ويستوي أن لن بأن

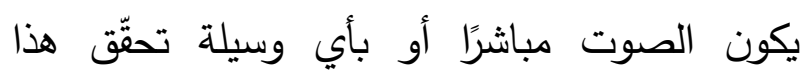
الغرض' ب- المصنفات الفنية: قد عرّفها المنظّم السعودي في

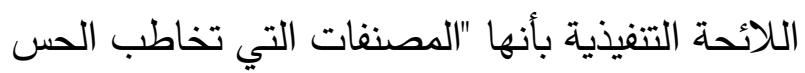

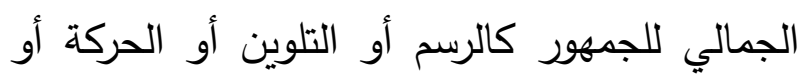

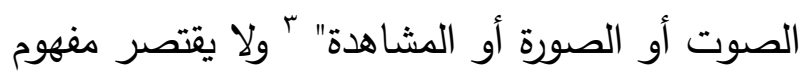
المصنفات فقط على أعمال الفنون الجميلة، بل يمتد ليشمل كافة المصنفات التي تظهر كإبداعات الأشكال،

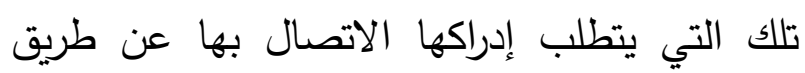

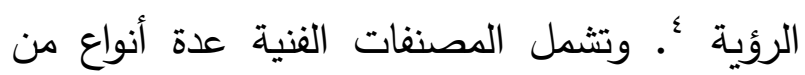
مصنفات الفنون التشكيلية والتطبيقية: كالرسم، النحت

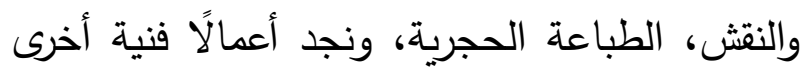
تدخل ضمن أعمال الهندسة المعمارية كالرسوم التخطيطية، والمخططات، والنماذج الهندسية.

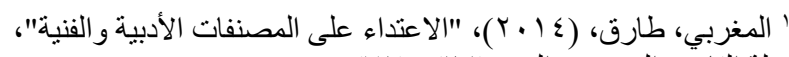

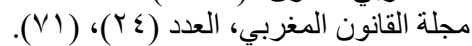

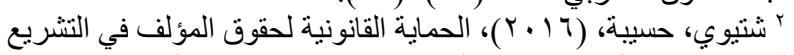

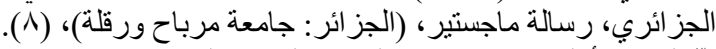

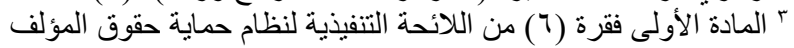

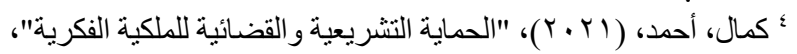

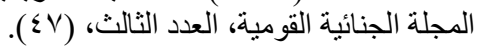


يستطيع أن يقوم بإضافة مبتكرة، وهذه الحالة لا تعتدُّ

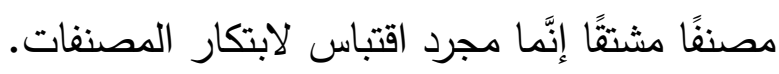

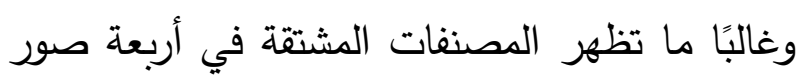
هي: إعادة إظهار المصنف الأصلي، أو إعادة إظهار

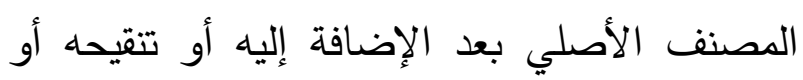
تحقيقه، أو إعادة إظهار المصنف عن طريق الاقتباس الاصن كالتلخيص مثلًا، أو إعادة إظهار المصنف إنهار عن طريق

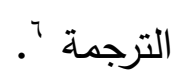

المبحث الثاني: طبيعة الابتكار في حقوق المؤلف وآثارها.

المصنفات الفكرية هي نتاج العقل البشري وإنَّ حقوق الملكية الفكرية تقوم على ركيزة أساسية هي أنّه لا أهم للإنسان من إنتاجه العقلي؛ لذا تكون هذه المصنفات

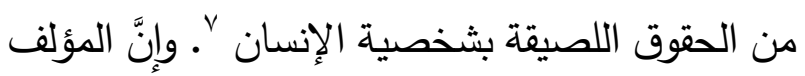

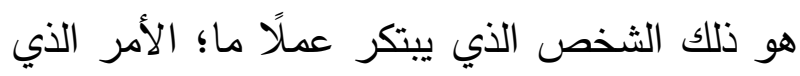

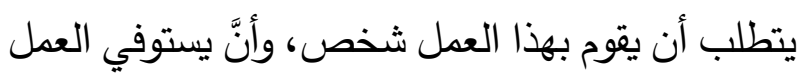

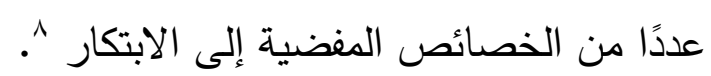

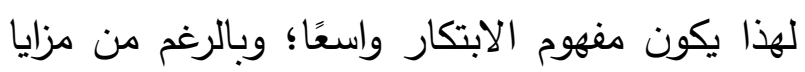

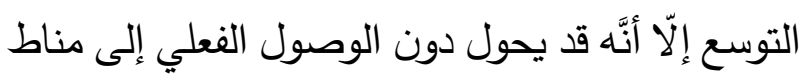

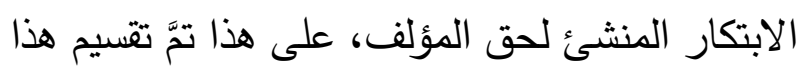
المبحث إلى مطلبين هما: معايير تحقّق الابتكار في

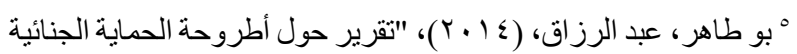

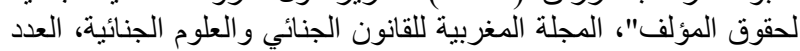

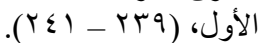

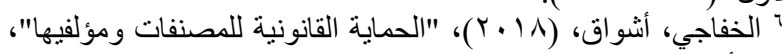

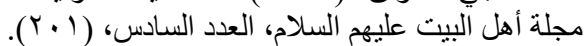

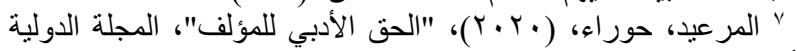

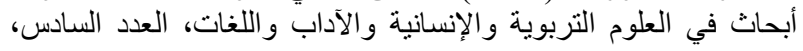
(IV.)

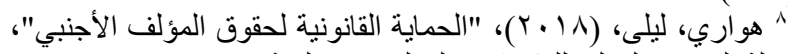

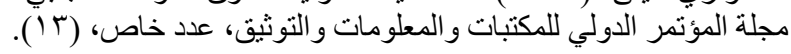

دائمًا ما تكون في علاقة تبعية للمصنفات الأصلية '.

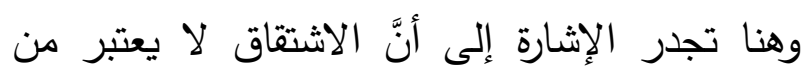

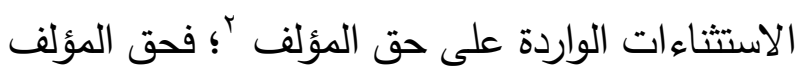

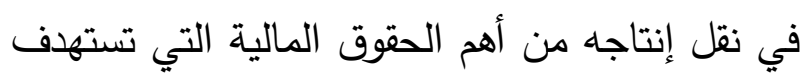

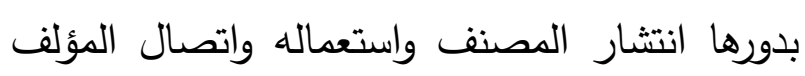
بصورة مباشرة ‘. وهنا تجدر الإشارة إلى شروط اعتبار المصنف مشتقًا؛ فلابد من توافر شرطين أساسيين

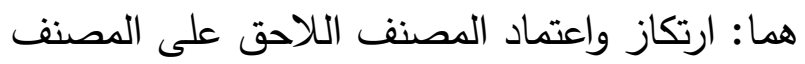

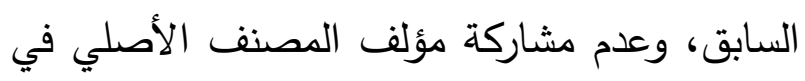

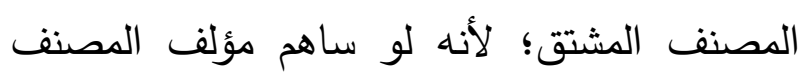

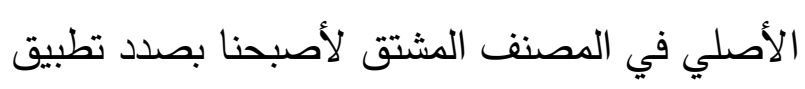

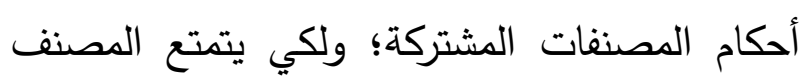

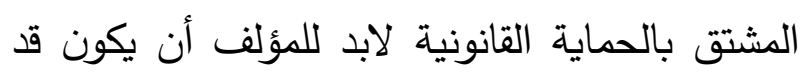

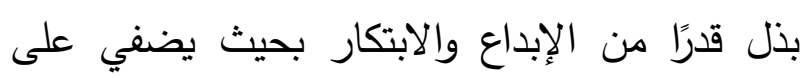

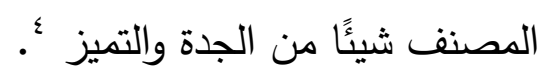

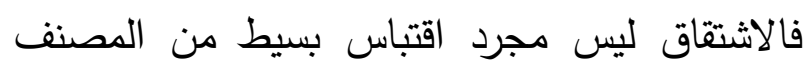
الأصلي؛ فمؤلف المصنف المشتق يقتبس عناصر

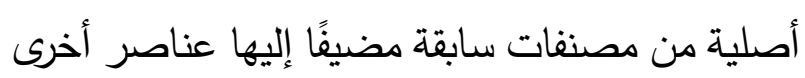

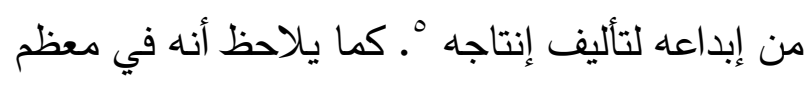

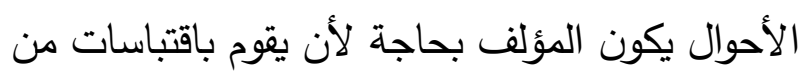

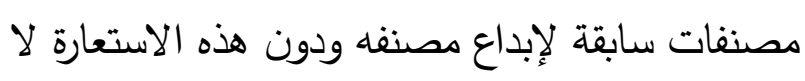

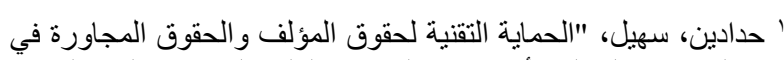

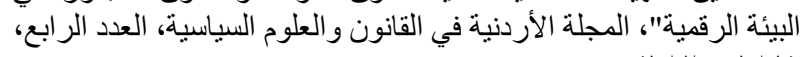

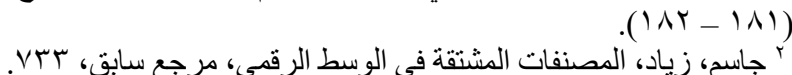

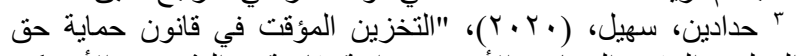

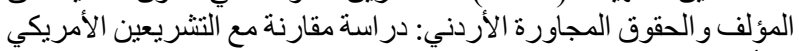

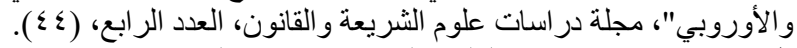

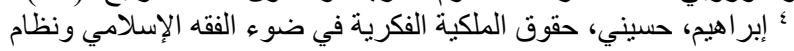
حقوق المؤلف السعودي، مرجع سابق، الهن، 11 ـ 79. 
شخصية مؤلفه، وأنَّ مفهوم الابتكار يتجلّى بأن يبرز

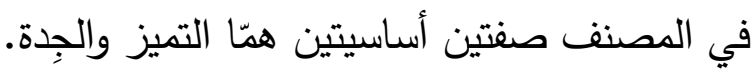
أولًا: الطابع الثخصي للمؤلف.

يقصد بالطابع الشخصي للمؤلف ظهور شخصية صاحب النتاج الفكري عند معالجته وإخراجه للفكرة

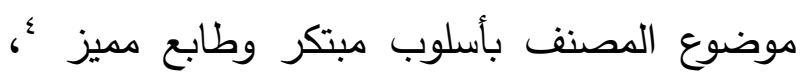

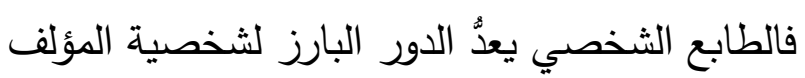

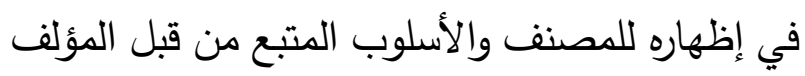
لنقل فكرة معينة، وهو الجها الذهني الذي يبذله

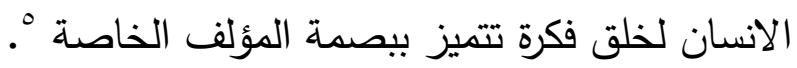
والمصنفات المحمية نظامًا هي المصنفات الفكرية المبتكرة التي تظهر إبداعات العقل البشري، التي تتجلى بصمتها الخاصة عبر قيام الإنسان بإنجاز

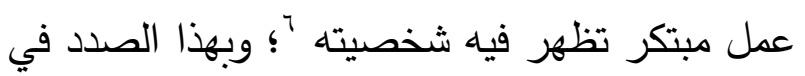

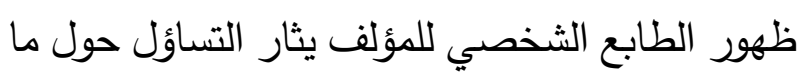

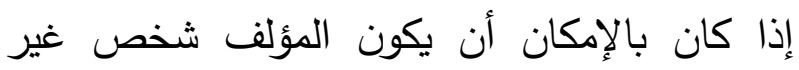

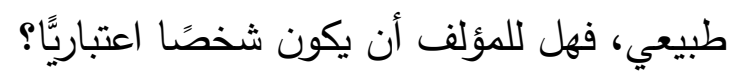

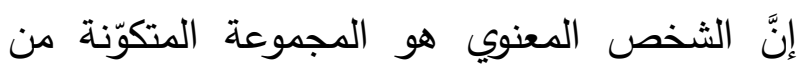

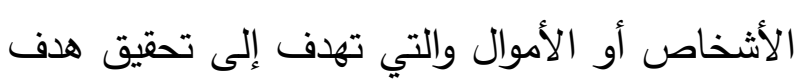

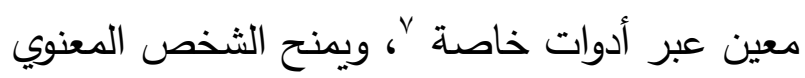

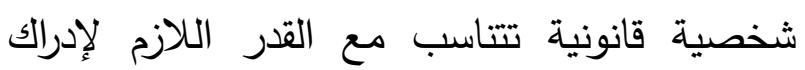

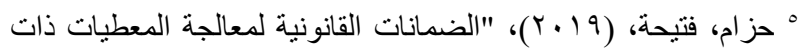

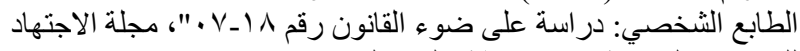

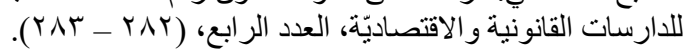

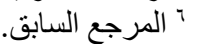

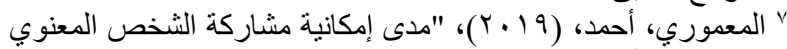

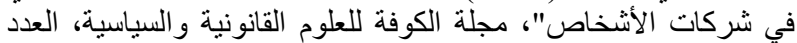

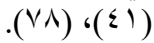

المصنفات، والآثار المترتبة عن الاعتماد الكلي على

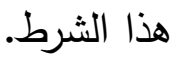
المطلب الأول: معايير تحقّق الابتكار في المصنفات الفكرية. يعدُّ الابتكار المعيار المميز لحقوق المؤلف والشرط الرئيسي لاستحقاق الحماية القانونية، ولا يلزم الابتكار

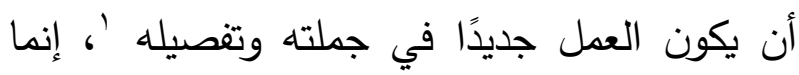
المراد منه أن يظهر المصنف الفكري بطابع يبرز

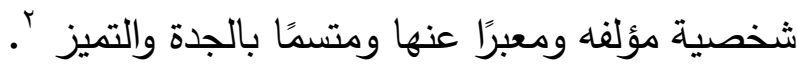
ولا يزال مفهوم الابتكار يشير جدلًا في المقصود به به باله وعلى هذا فإننا نعرض إلى الفرعين الآتيين بغية الوقوف على مناط الابتكار في حقوق المؤلف. الفرع الأول: إبراز شخصية المؤلف وظهور المصنف كثكل مادي. عرّف المنظّم السعودي الابتكار بأنَّه: "الطابع مادي الثخصي الذي يعرضه المؤلف في مصنفه الذي يعطي المصنف تميّزًا وجدة، ويبرز المصنف من لئن خلال مقومات الفكرة التي عرضها أو الطريقة التي وهي اتخذها لعرض هذه الفكرة" "َ؛ فنلحظ هنا أنَّ المنظّم السعودي قد عبّر عن الابتكار بأنّه منوط بالتعبير عن هن ان لهن

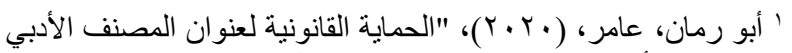

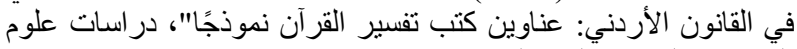

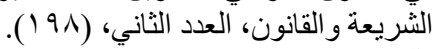

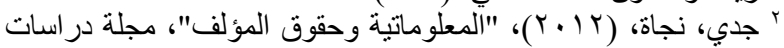

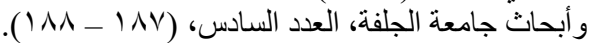

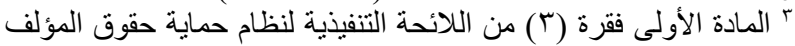

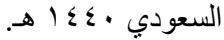

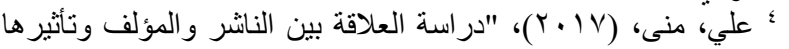
بالقانون الحالي للملكية الفكرية"، مجلة العمارة والفنون والعان والعلوم الإنسانية،

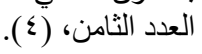


مالكًا لحق المؤلف كما هو الحال بالنسبة للمصنفات أو الأعمال الجماعية. وتأسيسًا على أن يكون قيام الإنسان بإنجاز المصنف الاعنف

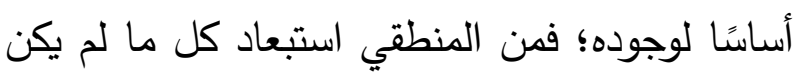
للإنسان يد فيه من نطاق حق المؤلف؛ فلا يعدُّ مصنفًا

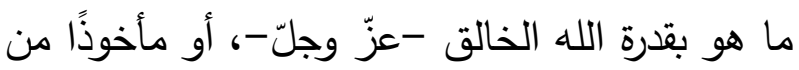
الطبيعة، أو بفعل العوامل البيئية، وكذلك الحال بالنسبة للأعمال المنجزة بواسطة الآلات أو البرمجيات وكلئه

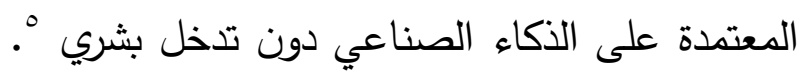

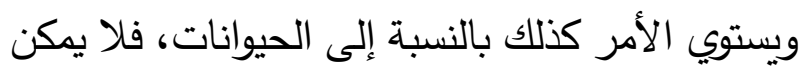

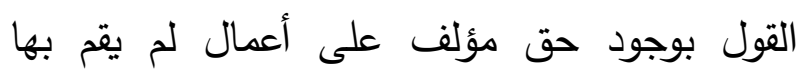
الإنسان؛ فإنَّ مناط اعتبار المصنفات مبتكرة؛ أن تتوافر لاى المؤلف إرادة الابتكار مما يعني أنه إذا مأنان

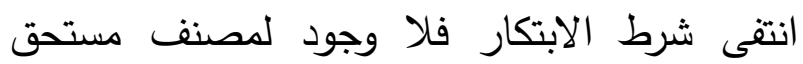

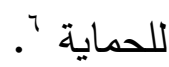

ثانيًّ: ظهور المصنف في شكل مادي محسوس.

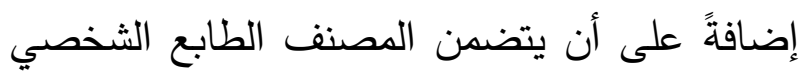

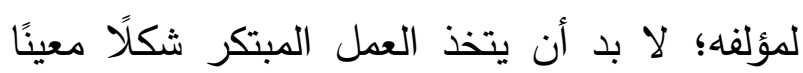

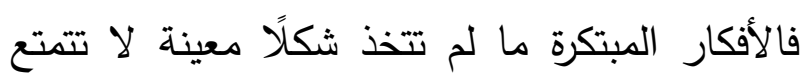

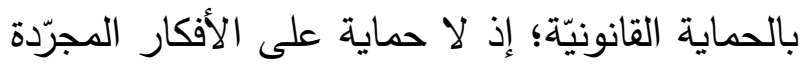

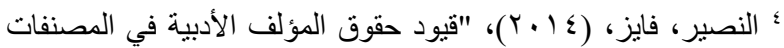

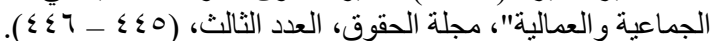

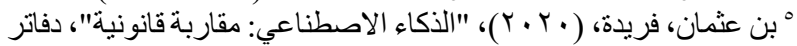

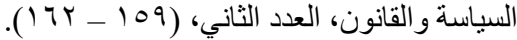

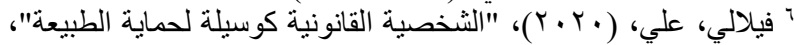

مجلة الاجتهاد للار اسات القانونية والاقتصادية، العدد الأول، (Y) (Y).
الهدف التي تكوّن من أجله '، وكان للفقه القانوني

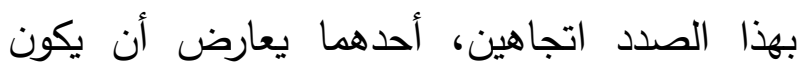

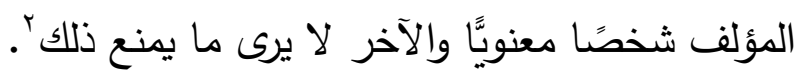

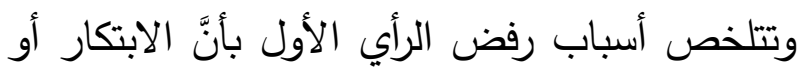

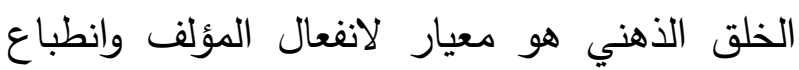

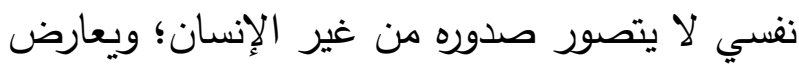

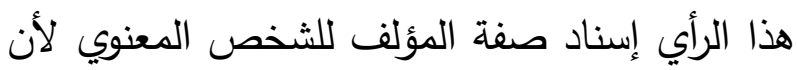

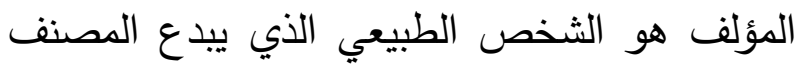

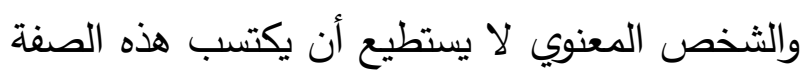

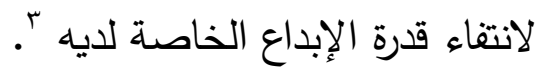

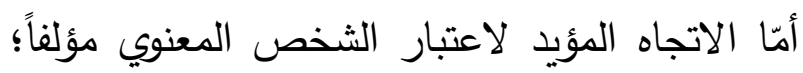
فلا تتوافر لديه أسباب الرفض السابق بيانها، ولا يرى لهاء

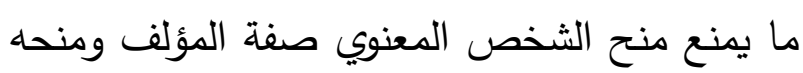

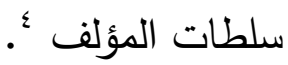
وفي نظر الباحثة لا يتصور إلّا أن يكون المؤلف

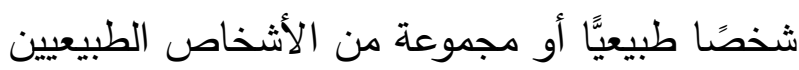

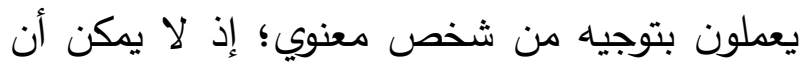

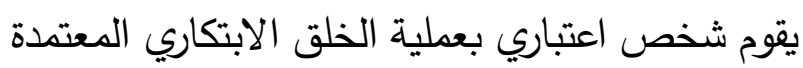

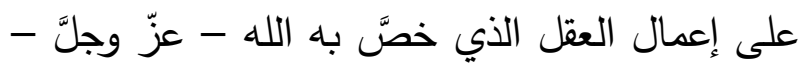

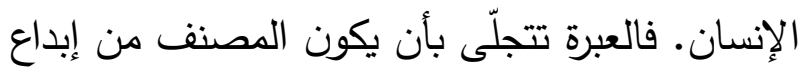

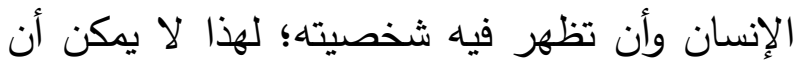
يكون المؤلف شخصًا معنويًّا، لكنه يمكن أن يكون

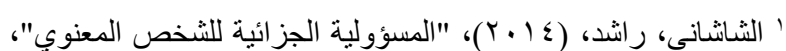

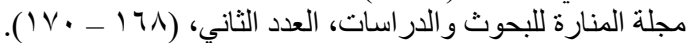

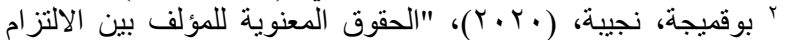

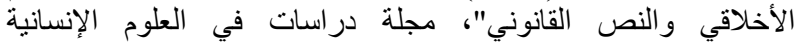

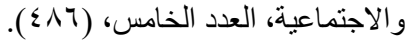

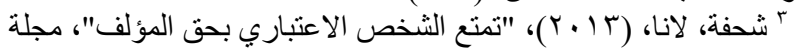

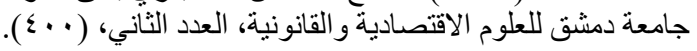


تأتي الإجابة عن هذا التساؤل حسب دور الصدفة في إنجاز العمل؛ فإذا كانت جزئية فلا تأثير لها على اعتبار العمل مصنفًا، أما إذا كان العمل هو وليد الصدفة كليَّا دون أن يكون هناك أي تدخل من قبل المؤلف؛ فلا يكون مصنفًا لعدم ظهور المصنف بطابع شخصية مؤلفه '. لهذا لا تعتبر الاكتشافات أحد المصنفات الفكرية؛ فتخرج من نطاق مفهوم حقوق المؤلف وذلك لاقتصار دور الإنسان فيها على إظهار ما هو موجود مسبقًا والكثف عن حقائق ثابتة دون أن يكون في هذا طابعه الشخصي المتسم بالابتكار '. وكذلك الحال بالنسبة لأعمال الفن المعاصر المعتمدة على مواد عضوية: كالرمل والخشب، فلا يمكن اعتبارها مصنفات، ولا حماية قانونية للمواد الأولية؛

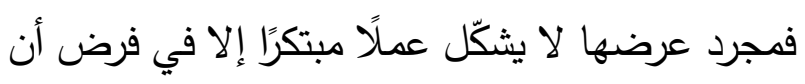
تخضع تلك المواد الأولية لتدخل بشري نتج عنه عمل مبتكر الفرع الثاني: الجدة والتميز كمحدِدات لابتكار المصنف الفكري.

عبّر المنظّم السعودي في تعريفه للابتكار عن سمتين أساسيتين تحدّدان مفهوم الابتكار، وهي أن يمنح الطابع الشخصي للمؤلف مُصنَفه تميّزًا وجدة؛ فمتى

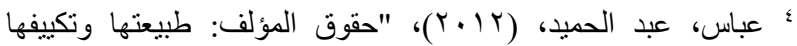

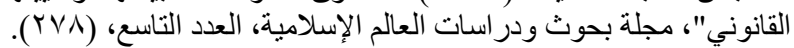

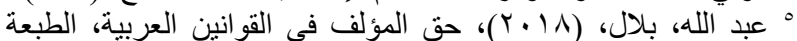

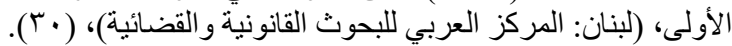

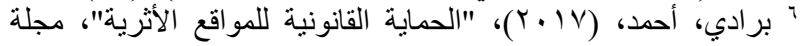

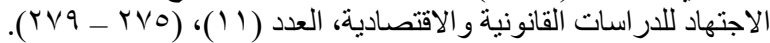

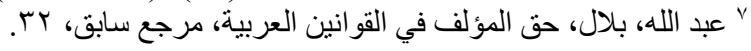

إنما تقع الحماية على شكل التعبير لا على الفكرة ذاتها ويظهر وجوب توافر الشكل لدى المنظّم السعودي من خلال تعريفه لمفهوم الابتكار ؛ والذي جاء فيه أن إبراز المصنف يكون من خلال مقومات الفكرة التي عرضها المؤلف أو بالطريقة التي اتخذها لعرض هذه الفكرة ‘ُ فالثرط الأول الذي يُبحَث لنشوء الحق هو وجود الشكل الذي يعبّر عن فكرة مبتكرة، وتتجلّى أهمية أن تتخذ الفكرة المبتكرة شكلً للتعبير عنها في إتاحة المصنف ليتمتع بقابلية النقل إلى الجمهور حتى يكون بمقدور الجمهور إدراكه ׳ّ وإنَّ الإدراك والإحساس لاى الإنسان يتم بواسطة حواسه الخمس لهذا يجب أن إن الن يكون الشكل محسوسًا ليتمكن الجمهور من تلقيّه. الأمر الذي يستلزم أن يكون الشكل المتخذ للتعبير عن من من لهن الفكرة جديرًا بالماحظة من قبل الغير ، فإذا ما انتفى

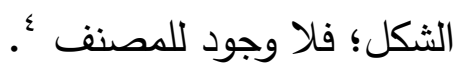
إذًا لابد لتحقّق الطابع الشخصي للمؤلف على مصنفه أن يقوم بإنجاز العمل إنسان وأن يعبّر عن فكرة مبتكرة في شكل معيّن، وهنا تثار مسألة مهمة تتعلق بإرادة الابتكار، وهي دور الصدفة في ابتكار العمل، فهل يؤثر ذلك على اعتبار المصنف الفكري مبتكرًا؟

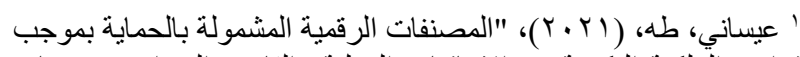

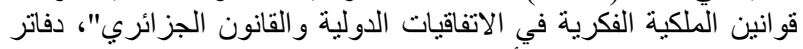

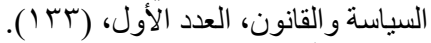

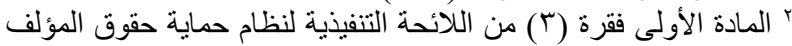

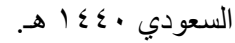

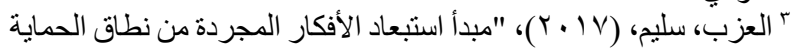

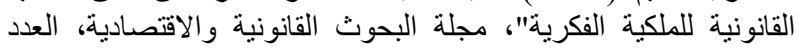

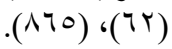


العمل عن غيره فحسب؟ وهل ينتفي الابتكار عن الأعمال المتداولة غير الجديدة؟ إنَّ تحديد معيار الجِدة يرتبط بعدة عوامل منها الحق

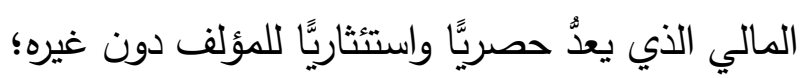
وتأتي الحصرية كمكافأة من المجتمع للمؤلف على

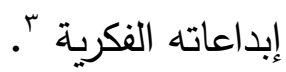
فتحقق الابتكار لدى المؤلف يستتد في أساسه على قاعدة التحفيز لما ينتجه من أعمال إبداعية؛ الأمر الذي ينعكس بدوره على مستوى الجدة في الأفكار التي

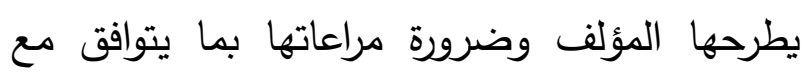
مبدأي الاستئثار والتحفيز ؛ ل. وفي هذا الصدد تجدر الإشارة إلى أنَّ المنظّم السعودي لم يحدّد مفهوم الجدة المقصود لحماية المصنفات الفكرية وكيف يتم قياسه ْ؛ إنمّا اكتفى بذكر الجدة كصفة تدل على تحقّق الابتكار في هذه المصنفات بالإضافة إلى التميّز ، وعليه فإننا نعرض إلى بعض معايير التحقّق من استيفاء صفة الجِدة لاعتبار المصنف مبتكرًا.

أ- معيار الجهد المستغرق لإخراج المصنفات: يعتمد هذا المعيار على مقدار وكيف الجهد المبذول في إخراج الأفكار بأسلوب خلّاق وطريقة متميزة جديدة تختلف عن الأفكار التي تتضمنها، ويرتكز هذا

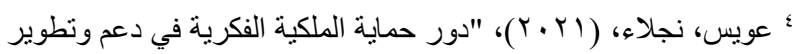

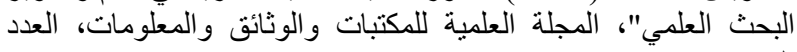

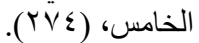

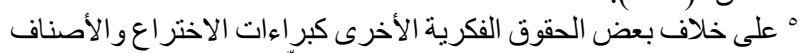

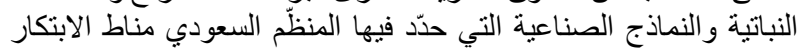
وبيّن طرق قياسه.
ما استوفت الأعمال المبتكرة -التي ظهرت كصورة محسوسة تعبّر عن شخصية مؤلفها - هذين المحددين فإنها تحمى بموجب نظام حقوق المؤلف.

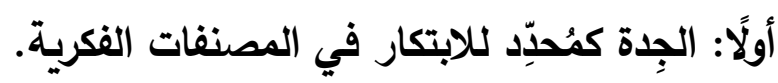
إنَّ مفهوم الجدة في حقوق المؤلف يثير جدلًا واسعًا؛ فالمبادئ الأساسية التي تبنى عليها الحماية القانونية: من ضرورة أن يعكس المصنف شخصية مؤلفه، وأن يتمَّ تجسيد هذا العمل على دعامة مادية محسوسة لعدية لإيصاله إلى الجمهور تحمل في طياتها ارتباطًا عميقًا بالإبداع' الأمر الذي يدعونا لبحث الغاية المباشرة من الحماية

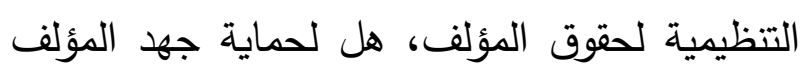

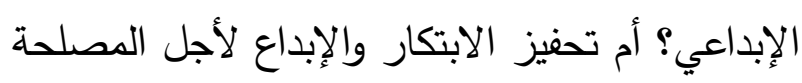
العامة؟ وحقيقية القول أنَّ النظام السعودي لحماية حقوق المؤلف جاء للموازنة بين هاتين الغايتين؛ ويمكننا اعتبار أنَّ الغاية الأولى هي الهدف المباشروله لين هاتين الغايثن؛

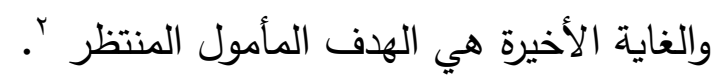

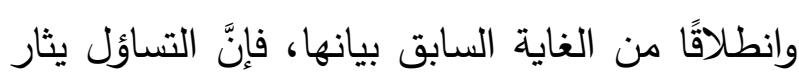
حول معيار الجِدة لضبط الابتكار ؛ هل المراد أن تكون

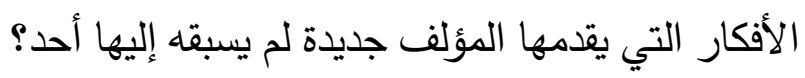

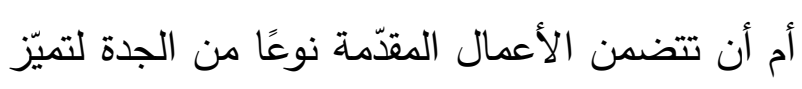

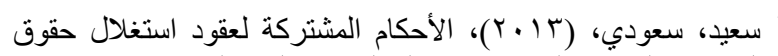

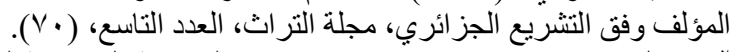

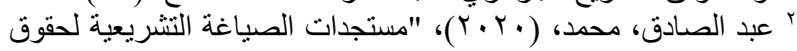
المؤلف والحقوق المجاورة في الكويت"، مجلة الحقوق، العدان، العدد الثاني،

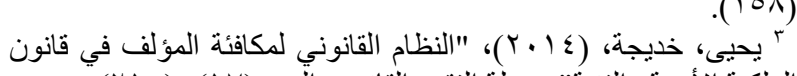

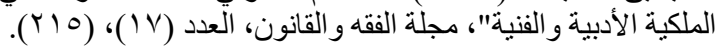


وترى الباحثة أن الجها وحده لا يمكن أن يعطي للأفكار والأعمال صبغة الابتكار للمصنفات الفكريّة

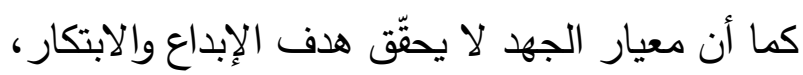

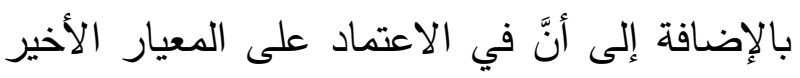

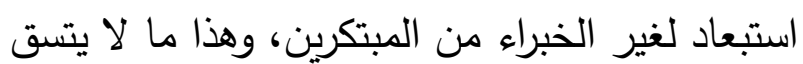
مع المراد من الابتكار وغاية تعزيزه.

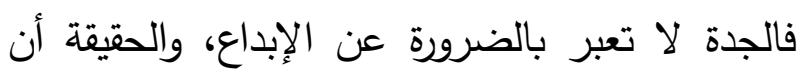
تطلب الجدة في المصنفات الفكرية كمعيار للحماية صعب التثّبت منه من الناحية العملية؛ أن هذه الأعمال - لاسيما الأدبية - تكون معتمدة على الخبرات والأفكار والتجارب السابقة، مستندةً إلى أفكار إبداعية متتوعة. وعلى الرغم من الارتباط الوثيق بين المصنف الفكري وشخصية المؤلف؛ إلا أن هذا النتاج الفكري لا بد من أن التأثر بالبيئة المحيطة وما ساهم

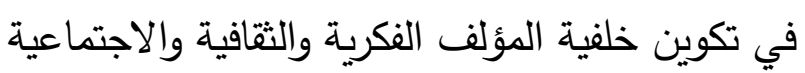
سواء من تجاربه الثخصية أو ممارساته العملية، أو

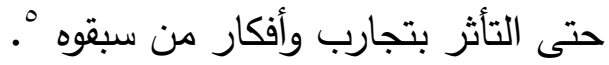

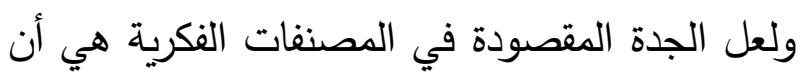
يضفي المؤلف على الفكرة طابعه الثخصي حتى وإن كانت الفكرة قديمة بشرط أن تتميز بطابعه؛ لأن الابتكار هو كل ما يعكس شخصية المؤلف في إنجاز عمل خاص به وهنا يتجلّى مفهوم الجدة في حقوق ئلئل

r أبو رمان، عامر ، "الحماية القانونية لعنوان المصنف الأدبي في القانون

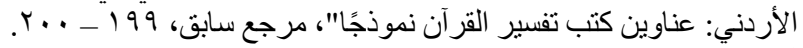

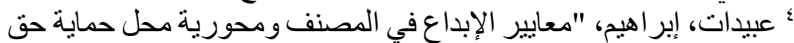

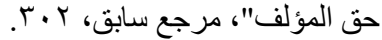

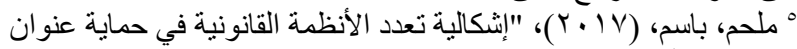
المصنف الأدبي و الفني"، مجلة كلية القانون الكويتية العالمية، العدد (10)،
المعيار بصورة أساسية على قدرات المؤلف والجهد الذي بذله حتى يتمكّن من إظهار الأفكار بأسلوب

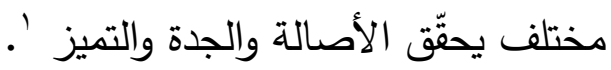
ويعتبر هذا المعيار أنَّ الجهد الذي تنَّ بذله في سبيل تجميع المعلومات والبيانات لإخراج العمل بشكل جديد متميز من شأنه أن يكون الغرض لاستحقاق الحماية القانونية، ويمكن قياس مدى استيفاء هذا المعيار بناءً على معطيات منتجة هي: الجهد المبذول، الزمن المستغرق، بالإضافة إلى النفقات التي تََّّ تكبّدها في التيات

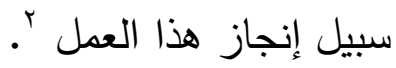
ويذهب هذا المعيار إلى إنَّ اختيار وتنقيح الأفكار

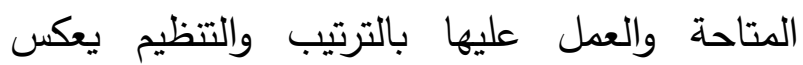
بالضرورة ضربًا من الجدة التي تستلزمها أصالة العمل؛ وهذا يعني أن الجدة تتحقق بأسلوب التعبير

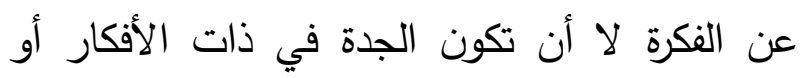

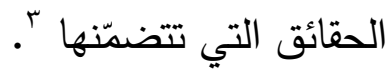

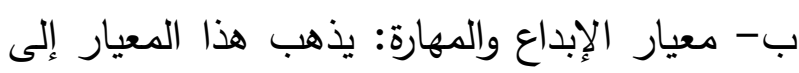
أنَّ المصنفات الفكرية تستحق الحماية القانونية شريطة

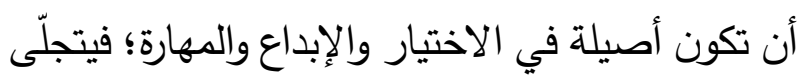

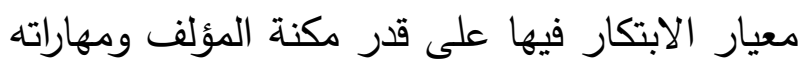
في إبداع الأسلوب الذي اتخذه في التعبير عن فكره ؛ـ

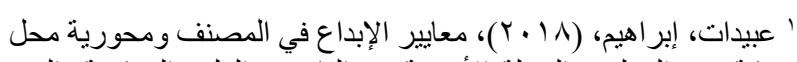

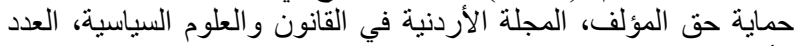

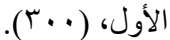

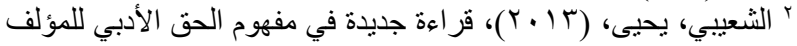

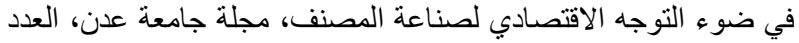
(r.r-r.r) (r) (r) 
حتى وإن تشابهت أفكار المؤلف مع أفكار سابقة طالما

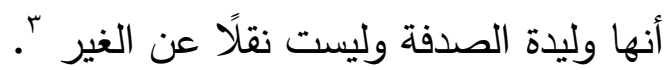

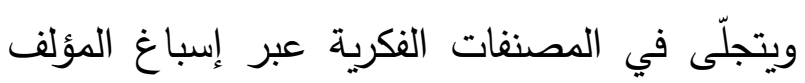
أسلوبه الخاص على المصنف من خلال طريقة وأسلوب التعبير عنه، وهو ذلك التثرّد هو الذي يظهر هن الروح الإبداعية التي تعكس أصالة العمل؛ فالتميّز

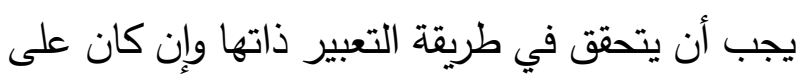
درجة بسيطة من الإبداع والابتكار ، كما يستلزم التميّز

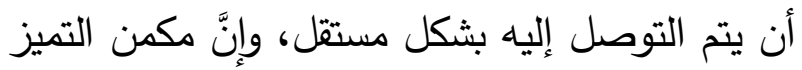

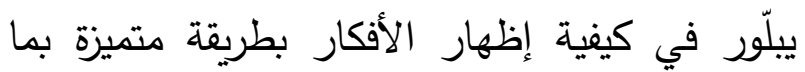
يعكس شخصية وذاتية صاحبها. فالمؤلف حينما يكرس مهاراته وجهده للتعبير عن أفكاره بطريقة متميزة مستقلة فإنه يستحق الحماية القانونية،

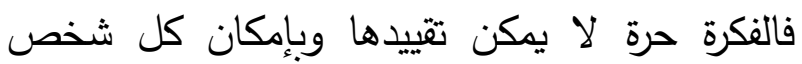
الوصول إليها؛ الأمر الذي لا ينطبق على طيلى طريقة التعبير عنها. فهنا يظهر تميّز المصنف التي تنَّ إخراج شكله أو عُبرَ عن مضمونه بشكل متميز مستقل، لفهير فالفكرة في ذاتها بسيطة وسهلة إنّما يكمن التحدي في ليخدي كيفية إخراجها بأسلوب مختلف يتسم بذاتية وشخصية

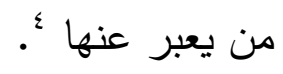

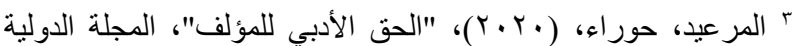
أبحاث في العلوم التربوية والإنسانية والآداب واللغات، العدد الساد، العال، (IVI) " عبيدات، إبر اهيم، معايير الإبداع في المصنف ومحورية محل حماية حق

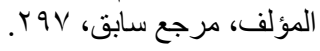

المؤلف؛ باعتبار العمل جديدًا عندما يحمل مساهمة فكرية للمؤلف، فالمساهمة تحمل شيئًا من الجدة. لذلك يمكننا القول بأنَّ مفهوم الجدة في تقرير الحماية وتحديد معيار الابتكار ؛ يكفي فيه أن يكون المصنف جديدًا بالمعنى الذاتي للكلمة، ولا حاجة لأن يكون جديدًا بالمعنى الموضوعي المطلق الذي يستلزم أن يستحدث الابتكار فكرة جديدة؛ وأن الجدة تتمثل في المساهمة الفكرية التي قدمها المؤلف والمتأثرة بما يحيط بالمؤلف وبمساهمات من سبقوه في المجال. ثانيَّا: التميّز كمُحدِّد للابتكار في المصنفات الفكرية. إنَّ الابتكار في المصنفات قد يكون مطلقًا أو نسبيًّا، وهذا التمييز هو أثر أن يتمَّ تقسيم المصنفات الفكرية إلى أصلية ومشتقة؛ فيكون الابتكار مطلقًا عندما يكون المصنف جديدًا كابداعٍ خالصٍ لمؤلفه، دون أن يرتبط أو ينبثق من أي عمل سابق، ويكون الابتكار نسبيًّا عندما يكون المصنف مستوحى من عمل سابق أو

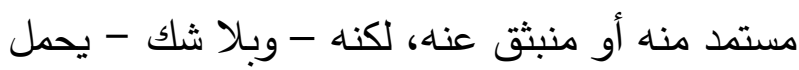
طابع مؤلفه الشخصي وبصمته الخاصة ' وإنَّ التميّز أهم متطلبات حماية حقوق المؤلف، ويراد به أنَّ المصنف الفكري يكون نابعًا من فكر المؤلف وأن يتم إظهار هذا الفكر في قالب متميز يعكس شخصية المؤلف وأسلوبه المستقل بَ، ويتحقّق التميّز

' الثيخ، طارق، (Y V V V)، "الحماية المدنية لأصحاب الأعمال الابتكارية

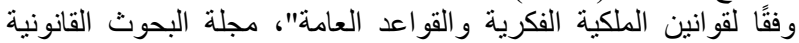

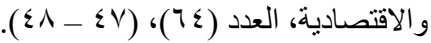

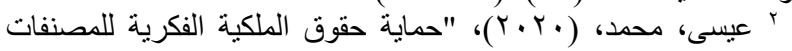

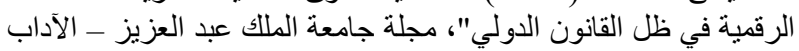
و العلوم الإنسانية، العدد السابع، ( • (V). 
قصيدة؛ فالابتكار كما تقدّم الذكر هو الثرط الأساسي الوحيد لحماية المصنفات، والمنظّم السعودي لم يستلزم شرطًا آخر أو صفة معينة لاستحقاق الحماية القانونية؛

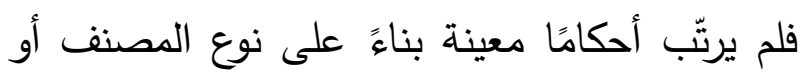
شكله أو قيمته أو غايته، وهذا يعني حماية المصنفات الفكرية بمعزل عن مواصفاتها '.

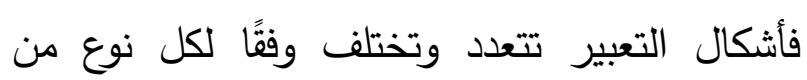
المصنفات والأعمال، فقد تكون طريقة التعبير شفهيّة كالمحاضرات أو خطية كالكتب '، وبالنسبة للمصنفات الفنيّة فإنَّ أشكال التعبير تأخذ صورًا متعددة لذات المدرسة الفنيّة فالرسم أنواع، والنحت أنواع، والزخرفة

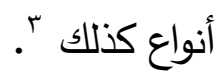
ثانيًا: حماية مقررة بمعزل عن قيمة المصنف وغايته. إن قاعدة عدم الاعتداد بقيمة المصنف في تقرير الحماية؛ تعني أنَّ القانون لا يقر الحماية للإبداعات

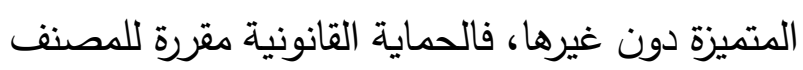
المبتكر بصرف النظر عن شهرة مؤلفه ودون الاعتداد

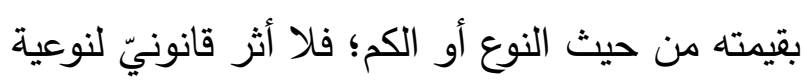
للعمل أو المصنف سواء كانت جيدة أم رديئة ؛.

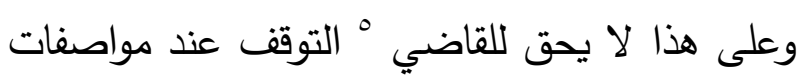
المصنف أو شكله أو قيمته في تقريره للحماية القانونية

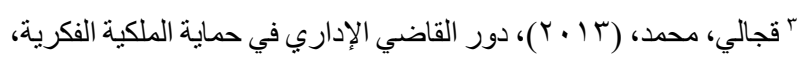

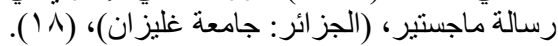

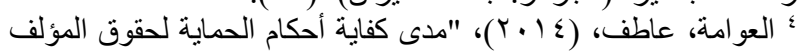

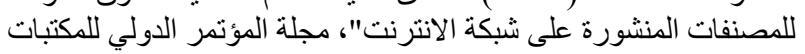

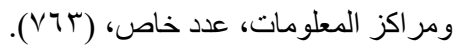
• عبد الله، بلال، حق المؤلف في القوانين العربية، مرجع سابق، هـ ــ
المطلب الثاني: الآثار المترتبة عن الاعتماد الكلي

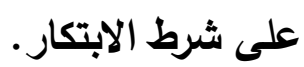
إن المصنف المحمي قانونيًّا بموجب حقوق المؤلف هو ذلك المصنف المبتكر الذي أخذ صورة ماديّة

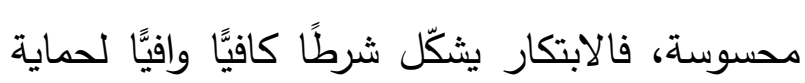

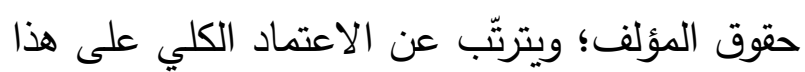

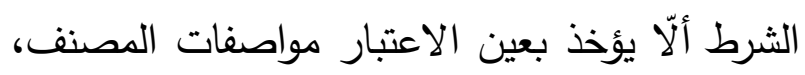
وألّا يشترط القيام بأي إجراء شكلي آخر لاستحقاق الاعتئ الحماية القانونيّة. الفرع الأول: حماية قانونية للمصنف بمعزل عن أي شرط آخر. إنَّ حماية الابتكار وتشجيعه تستوجب ألّا يتم احتكار الحماية القانونيّة لمصنفات دون الأخرى، فالإبداع مطلوب في شتى المجالات التي تمسُ حياة الإنسان.

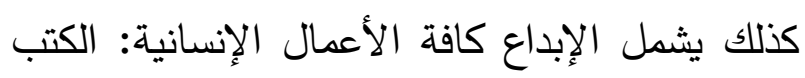

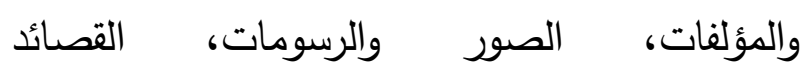
والمحاضرات، وحتى برمجيات الحاسوب والتصاميم المعمارية؛ فالابتكار مستمر ببقاء الإنسان.

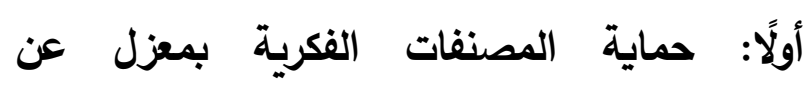
المواصفات. إن الحماية القانونية مقرّرة لجميع إنتاجات العقل البشري بصرف النظر عن أسلوب إخراجها أو طريقة

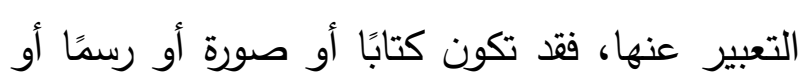

' إبر اهيم، حسيني، حقوق الملكية الفكرية في ضوء الفقه الإسلامي ونظام

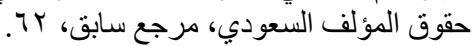

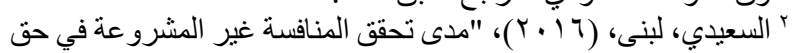

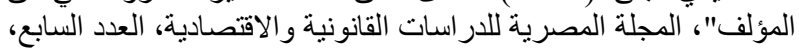


يعرف بالحماية التلقائية؛ الذي يقتضي أن تتمتع المصنفات الفكرية بالحماية القانونية لمجرد ظهورها كواقع مادي متصف بالابتكار دون الحاجة إلى أي إجراء آخر •

أولًا: حماية قانونية للمصنف دون التسجيل. إنَّ بعض التشريعات الخاصة بالملكية الفكرية لانية تكتفي بالتعبير عن الأفكار المبتكرة في شكل مادي محسوس حتى تكتسب المصنفات بذلك الحماية القانونية، بل تستلزم الالتزام بإجراءات شكلية معينة تتمثل في تسجيل المصنف؛ فتسجيل المصنف بهذا يكون شرط أساسي لاستحقاق الحماية القانونية؛ فيلتزم المؤلف بتسجيل جميع البيانات المتعلقة بالمصنف في السجلات المخصصّة لهذا الغرض ْْ . وهنا نغرق بين تسجيل المصنف وبين الإيداع القانوني للمصنف، فالأخير هو مجرد إجراء وقائي للحيلولة دون وقوع الاعتداء على المصنفات، فهو إجراء يلتزم بمقتضاه المؤلفون بالتضامن فيما بينهم بتسليم عدد محدد من نسخ المصنفات لإحدى الجهات الحكومية أو إحدى المكتبات الوطنية '. ومن الجدير بالذكر أنَّ المنظّم السعودي لا يستوجب التسجيل لحماية حق المؤلف، فأي مصنف يتمتع بالإضافة الابتكارية وتم إخراجه كقالب مادي فهو

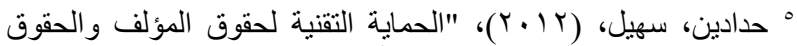

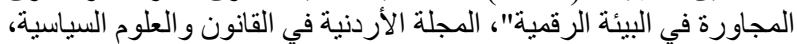

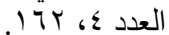

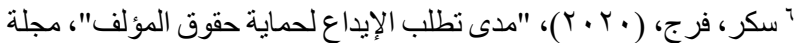

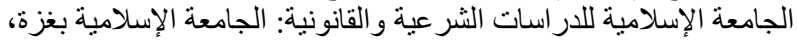

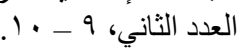

'؛ وإلّا لارتبطت الحماية بذوق وميول القاضي، الأمر الذي يؤدي إلى الإخلال بالمساواة بين المؤلفين أمام القضاء؛ فدور القاضي هو بحث مدى تحقق الابتكار

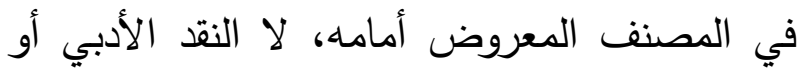
الفني. ويأتي الاختصاص باعتبار قاضي الموضوعي الهي

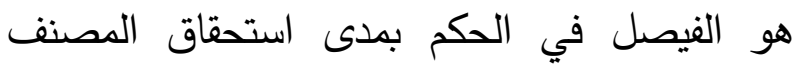

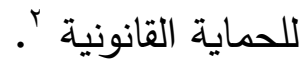
إلّا أنَّ للقاضي الحكم بعدم مشروعية المصنف؛ عبر

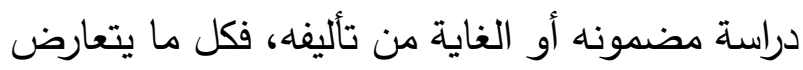

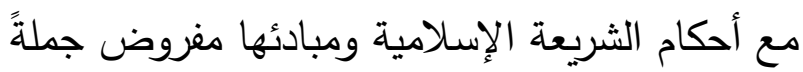
وتفصيلً، كذلك ما يخالف النظام العام أو الآداب

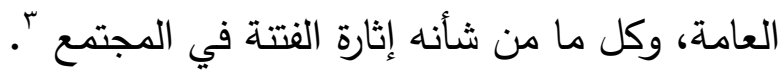
وتجدر الإثارة أنَّ في صرف النظر عن الغاية من النان

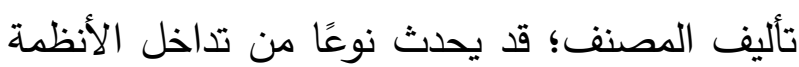
المختصة بالحماية، كما هو الحال بالنسبة إلى تصاميم

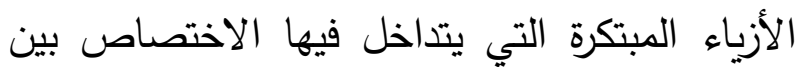
نظام حماية حقوق المؤلف ونظام حماية النماذج الصناعية ؛ نطائ. الفرع الثاني: حماية قانونية للمصنف بمعزل عن أي إجراء آخر إنَّ الاتفاقيات الدولية التي جاءت لغرض لغراء توحيد الجهود في سبيل حماية حقوق المؤلف قد أقرّت مبداً دوليَّا

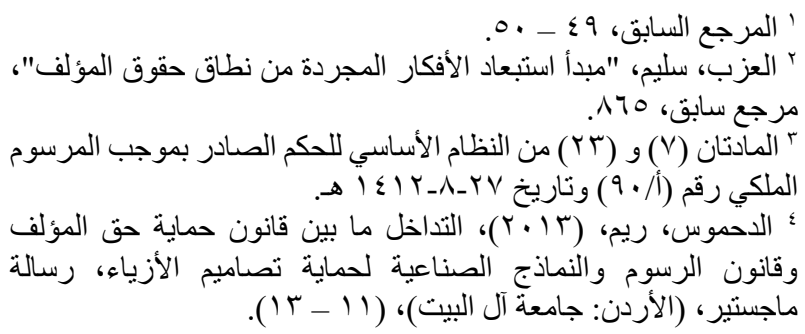


بيانه سابقًا من حماية المصنفات الفكرية دونما تسجيل؛ فالابتكار وحده يكفي ". أهّا مبدأ استقلالية الحماية فيراد به أنَّ الحماية القانونية للمصنّف لا تتوقف عند حدود الحماية الممنوحة في بلد المنشأ للمصنف؛ إنما تتجاوز ذلك إلى كافة الدول

المنضمة إلى الاتفاقية `. وتبعا لهذا فإن نطاق الحماية ووسائل الطعن المقرة النعايه

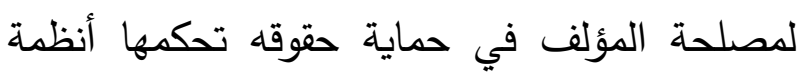
الدول المطلوب توفير الحماية القانونية فيها؛ إلّا أنَّ هذه الحماية تبقى في حدود الحد الأدنى للحماية

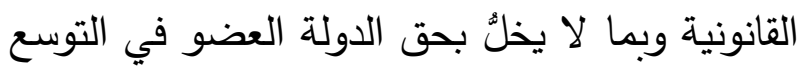

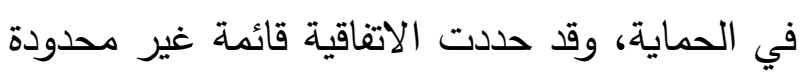
بالمصنفات التي تشملها الحماية في المجال الأدبي

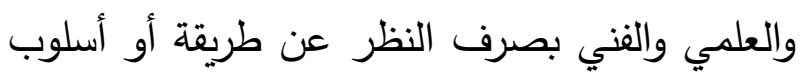

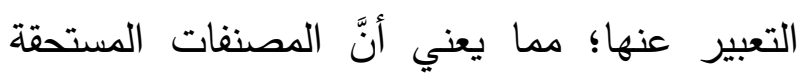

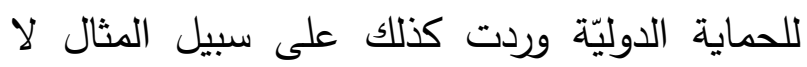
الحصر ـ أمّا مبدأ المعاملة الوطنية فيراد به أن تمنح الدول ذات معاملة مواطنيها المؤلفين في حماية مصنفاتهم الفكرية إلى مواطني الدول الأعضاء في موطنيا لدولين

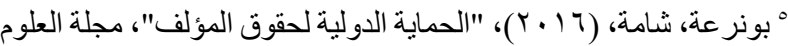

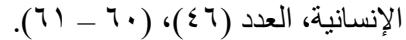

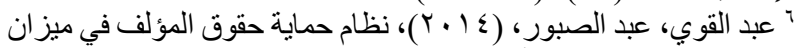

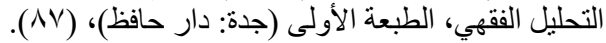

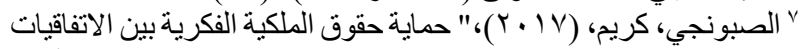

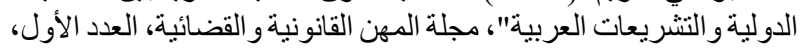

متمتع بالحماية القانونية دون الحاجة إلى أي إجراء آخر؛ إلّا أنه بعد تأسيس الهيئة السعودية للملكية

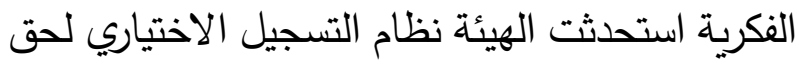
المؤلف؛ الذي يهدف إلى توفير مزيد من الحماية عبر منح المؤلف وثيقة ثبوتية تقضي بملكية المؤلف لهذا

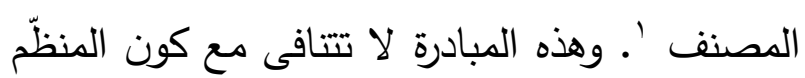
السعودي لم يستلزم إجراءات لمنح الحماية القانونية؛

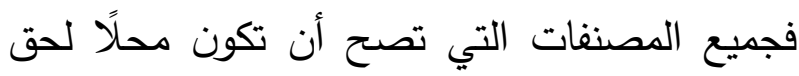
المؤلف هي محمية بموجب النظام ولا يجوز التعدي عليها شريطة أن تكون ذات طابع ابتكاري وأن يكون قد تم إخراجها في قالب مادي ولا عبرة بكونها لا تزال

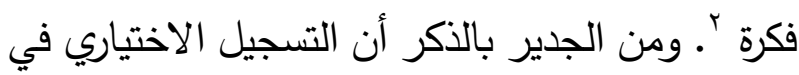

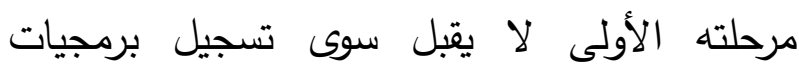

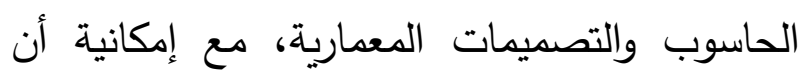
يشمل بقية مسارات حقوق المؤلف عند صدور قرار بذلك من رئيس الهيئة ‘ّ. ثانيًّا: الحماية الدولية للمصنفات الفكرية. إنَّ اتفاقية حماية المصنفات الأدبية والفنية برن ؛ قداند قامت على ثلاثة مبادئ دولية رئيسية هي مبدأ استقلالية الحماية، مبدأ المعاملة الوطنية، ومبدأ الحماية التلقائية أو الحماية دون تطلّب إجراء شكلي

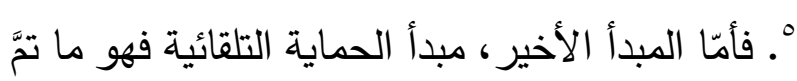

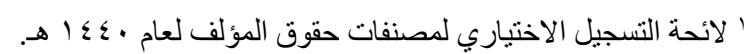

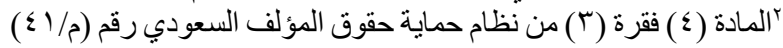

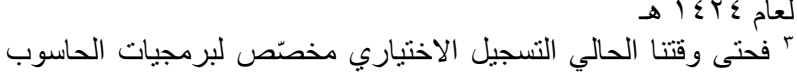
و التصاميم المعمارية. ؛ انضمت المملكة العربية السعودية إلى اتفاقية برن للمصنفات الأديبة

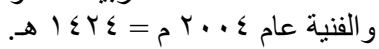


عنها، وتتقسم إلى طائفتين رئيسيتين هما: المصنفات الأصلية، والمصنفات المشتقة.

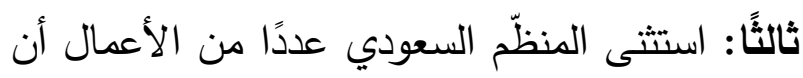
تكون محلًا لحق المؤلف كالوثائق الرسمية وأساليب العمل؛ لاعتبارات منها: ألّا تكون هذه الأعمال التي جاءت من أجل الصالح العام حكرًا للمؤلف؛ ولئلا يكون في إضفاء الصبغة القانونية صعوبة في التطبيق

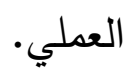

رابعًا: استثىى المنظّم السعودي الأخبار والنشرات من أن تكون محلًا لحق المؤلف؛ وقد أحسن في استدراك

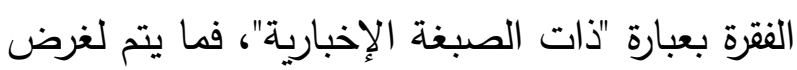

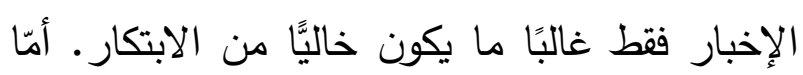

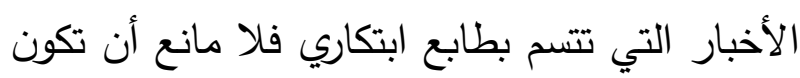
محلًا لحق المؤلف. الته

خامسًا: تَرِدُ بعض القيود على حق لقَ المؤلف؛ وهي

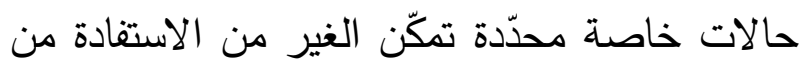
المصنف بما لا يتعارض مع حقوق المؤلف الأدبية، كتراخيص الترجمة والاستتساخ، الاقتباسات، واستخدام المصنفات لأغراض التعليم.

سادسًا: لا يلزم الابتكار أن يكون العمل جديدًا في لاعني

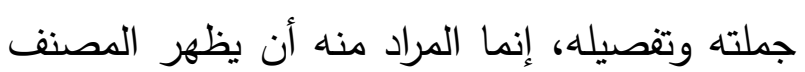
الفكري بطابع يبرز شخصية مؤلفه ومعبرًا عنها ومتسمًا بالجدة والتميز • ويشكّل الابتكار شرطًا كافيَّا

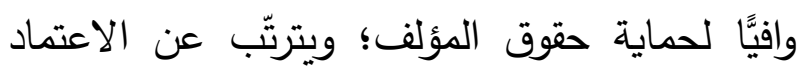
الكلي على هذا الشرط ألّا يؤخذ بعين الاعتبار
هذه الاتفاقية؛ فتسري عليهم قواعد وشروط الحماية

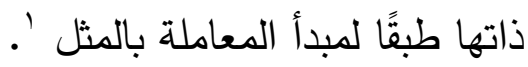
الخـاتمـة

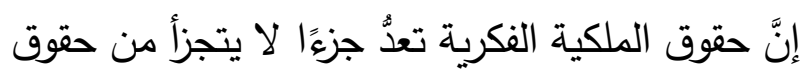
الإنسان لاسيما تلك الحقوق اللصيقة بشخصيته وتقوم على مبدأ ألّا أهم للإنسان من ثمرة فكره التي أخرجها إلى الوجود فضل إعمال ما وهبه الله من مكنة إعمال

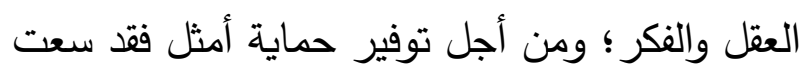
هذه الدراسة إلى بيان القيمة القانونية للابتكار في وني

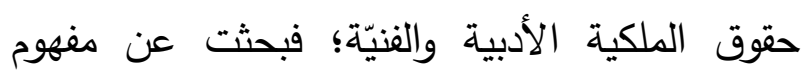
المؤلف ومفهوم المصنفات الفكرية؛ لتقف بعدها على الى ونى دور الابتكار فيها. وقد توصلت الدراسة إلى عدد من النتائج لعل من أبرزها ما يلي: - أوفات أولًا: يمتدُّ مفهوم المؤلف ليشمل كل من ينّا ينتج إنتاجًا ذهنيَّا بصرف النظر عن نوعه؛ باستثناء المخترعين ومبتكري العلامات التجارية وغيرهم الذين يخضعون لأحكام خاصة. والمؤلف هو كل من ينتج إنتاجًا مبتكرًا في مجالات الثقافة المختلفة ويظهر في نتاجه طابعه الميّز

ثانيًّا: تعرف المصنفات الفكرية لدى المنظّم السعودي بأنَّا محل الحماية القانونية، وهي تلكئك الإنتاجات

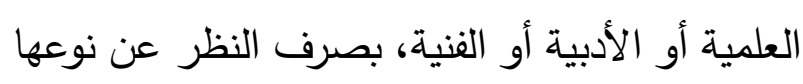

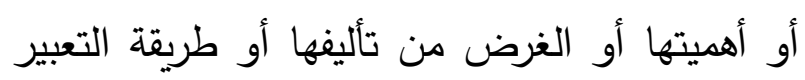

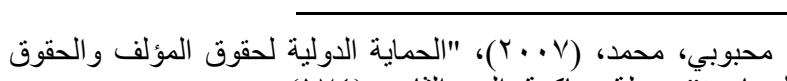

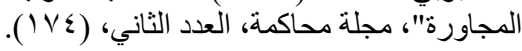


تكون عرضة للمنافسة غير المشروعة؛ فاستبعادها كان لغرض عدم اتساقها مع مفهوم حقوق المؤلف؛ عليه نوصي وزارة الإعلام والثقافة بالعناية بتظظيم هذا

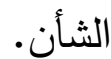

ثالثًا: نوصي الهيئة السعودية للملكية الفكرية بإتاحة تسجيل جميع المصنفات ضمن لائحة التسجيل الاختياري؛ نظرًا للفوائد التي يحققها من تقليص مدة القضاء وتوفير حماية أمثل. رابعًا: نوصي اللجنة الدولية الممثلة للمملكة في اتفاقيات ومعاهدات حماية حقوق المؤلف بإعادة النظر حول مبدأ "الحماية التلقائية"، واقتراح أن يكون هناك تسجيل عالمي للمصنفات الفكرية؛ نظرًا للميزات التي تتيحها لائحة التسجيل الاختياري وللأعباء التي تلافتها.

\section{المراجح}

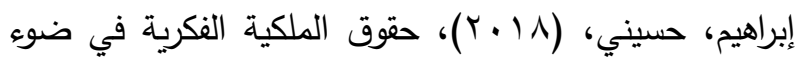
الفقه الإسلامي ونظام حقوق المؤلف السعودي، الطبعة

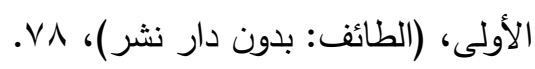

أبو بكر، محمد، (·r.r.r)، "عقود النشر ودورها في تشجيع الابتكار للمؤلفين"، مجلة دراسات في العلوم الإنسانية

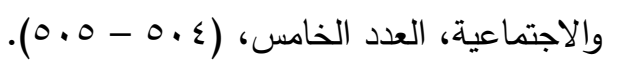

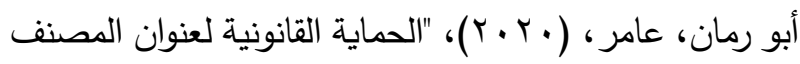
الأدبي في القانون الأردني: عناوين كتب تقسير القرآن

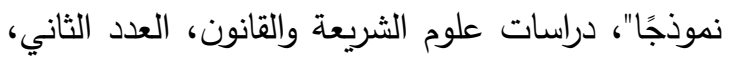

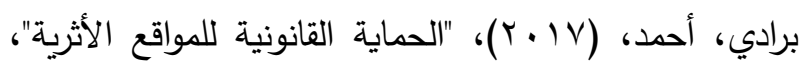
مجلة الاجتهاد للدراسات القانونية والاقتصادية، العدد العداه

$$
.(r \vee q-r \vee O) \cdot(1)
$$

مواصفات المصنف، وألّا يشترط القيام بأي إجراء شكلي آخر سابعًا: عبّر المنظّم السعودي عن الابتكار بأنّه منوط بالتعبير عن شخصية مؤلفه، وأنَّ مفهوم الابتكار يتجلّى بأن يبرز في المصنف صفتين أساسيتين همّا التميز والجدة، أمّا الطابع الشخصي فهو الدور البارز لشخصية المؤلف في إظهاره للمصنف. ويقصد بالجدة أن يكون المصنف جديدًا بالمعنى الذاتي للكلمة، ويتمثل ذلك في المساهمة الفكرية التي قدمها المؤلف. ثامنًا: لا بد أن يتخذ العمل المبتكر شكلً معينًا، فالأفكار المبتكرة ما لم تتخذ شكلً معينة لا تتمتع بالحماية القانونيّة؛ إذ أنَّ الحماية القانونية ترد على شكل التعبير لا على الفكرة ذاتها، والابتكار في المصنفات قد يكون مطلقًا أو نسبيًّا؛ فيكون الابتكار مطلقًا عندما يكون المصنف جديدًا كابداعٍ خالصٍ لمؤلفه، ويكون الابتكار نسبيًّا عندما يكون المصنف مستوحى من عمل سابق.

ومن النتائج السابق بيانها نوصي بما يلي: أولًا: نوصي المنظّم السعودي بالتعبير عن مفهوم الابتكار في حقوق المؤلف باصطلاح "الأصالة" فهي تقتضي أن يكون المصنف جديدًا نسبيَّا وقد تجلّت فيه بصمة المؤلف الخاصة؛ وبما لا يثير خلافًا حول المراد بمعياري الجدة والتميز اللذان عبّر عنهما كمحدات لمفهوم الابتكار في حقوق المؤلف. ثانيَّا: إنَّ استعباد الأخبار والنشرات ذات الصبغة الإخبارية من أن تكون محلً لحق المؤلف لا يعني أن الن 
جامعة نايف للعلوم الأمنية، (ع . . Y)، حقوق الملكية الفكرية،

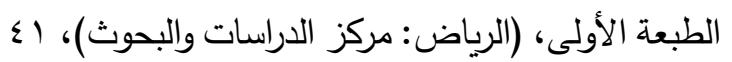

$$
\text { . }\{Y-
$$

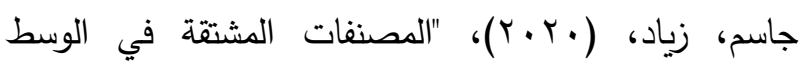

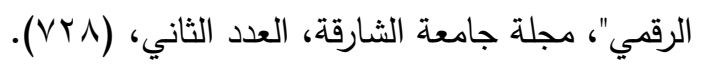

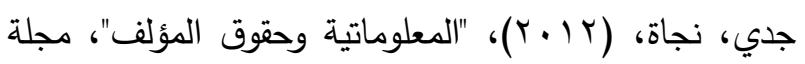

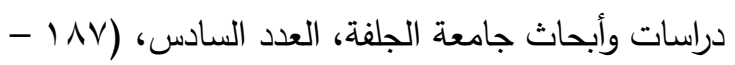
( ( ) ^ᄉ

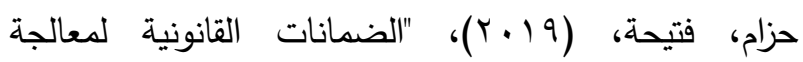
المعطيات ذات الطابع الشخصي: دراسة على ضوء

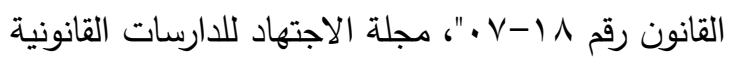

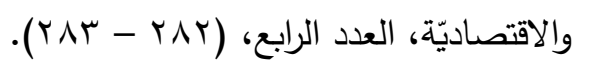

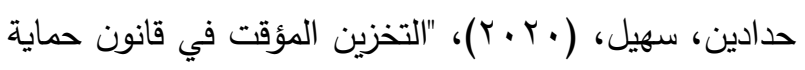

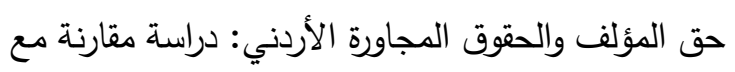

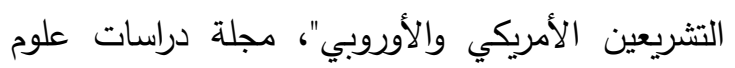

$$
\text { الشريعة والقانون، العدد الرابع، (ع ع). }
$$

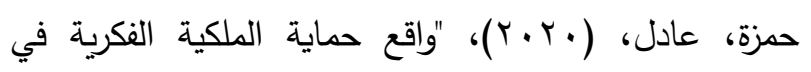
المشروعات الرقمية للجامعات السعودية"، مجلة جيل وانعايه

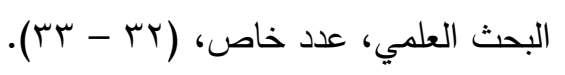

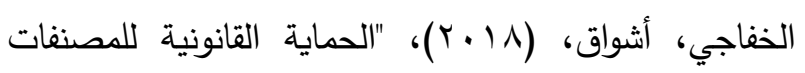

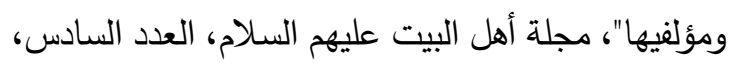

$$
\cdot(r \cdot 1)
$$

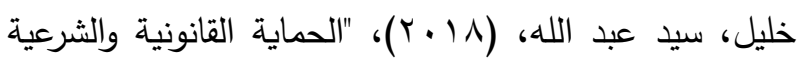

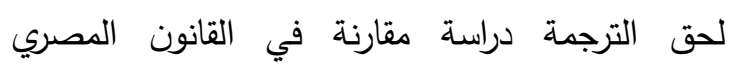
والسعودي"، مجلة كلية الثريعة والقانون بطنطا: جامعة

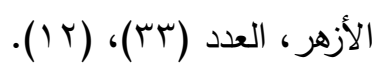

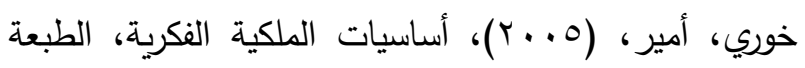
الأولى، (مصر: منشورات مكتب براءات الاخترات العترات

$$
\text { والعلامات التجارية للولايات المتحدة)، } 1 .
$$

البريكة، خلود، (T 1 • ب)، "الجوانب القانونية والأخلاقية في النشر الاككتروني"، مجلة المكتبات والمعلومات والتوثيق

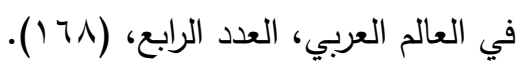

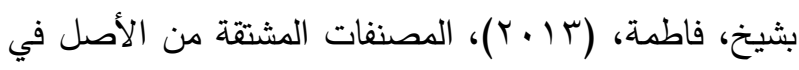
قانون الملكية الأدبية والفنية، رسالة ماجستير ، (الجزائر:

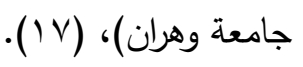

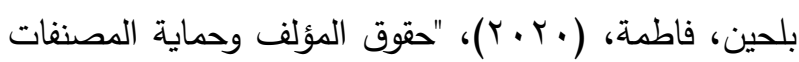
الرقمية في شبكة الانترنت"، مجلة المؤتمر الدولي المحكم في الملكية الفكرية على المؤلفات - مركز جيل البحث التبن

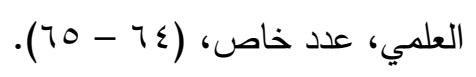

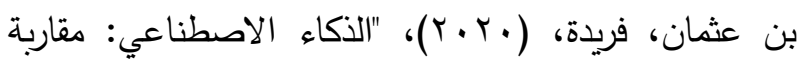

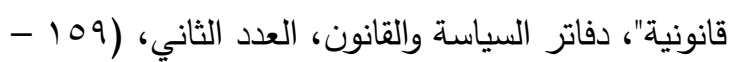

. (1)

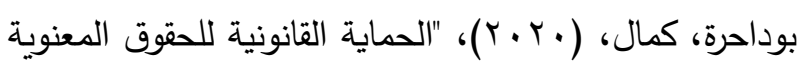
للمؤلف في القانون الجزائري"، دفاتر السياسة والقانون،

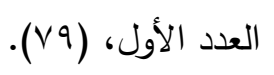

بو طاهر ، عبد الرزاق، (ع ا • r)، "تقرير حول أطروحة الحماية الجنائية لحقوق المؤلف"، المجلة المغربية للقانون الجنائي

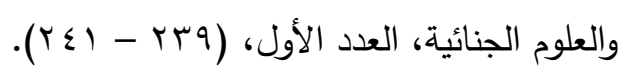

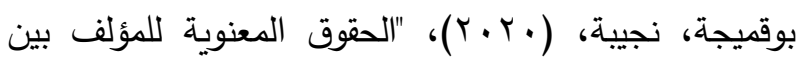

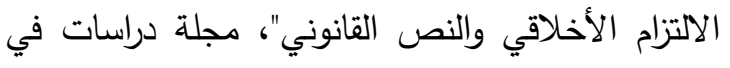

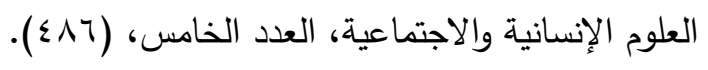

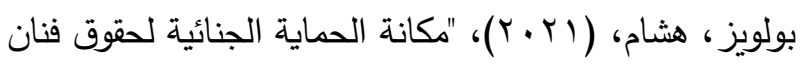

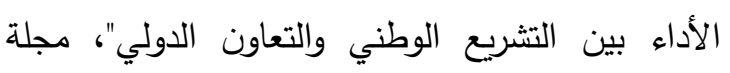

$$
\text { قانونك، العدد الخامس، (Y (Y). }
$$

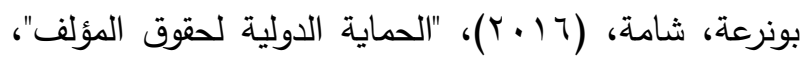

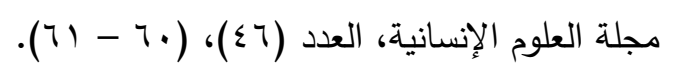

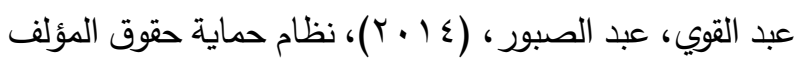
في ميزان التحليل الفقهي، الطبعة الأولى (جدة: دار

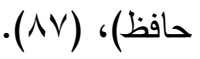




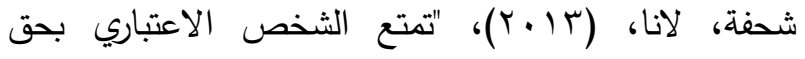
المؤلف"، مجلة جامعة دمشق للعلوم الاقتصادية

$$
\text { والقانونية، العدد الثاني، ( . . ع). }
$$

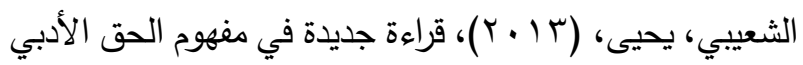

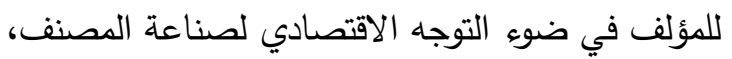

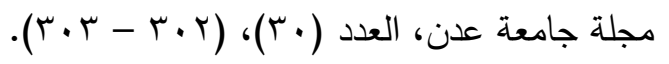

شلبي، إلهام، (· ( • (Y)، "دليل حقوق الملكية الفكرية: معيار

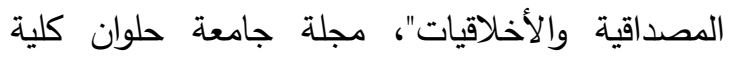

$$
\text { الشريعة بالجزيرة، عدد خاص، ( • (). }
$$

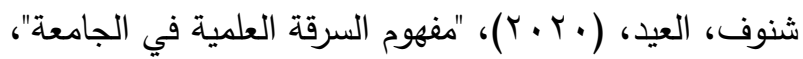

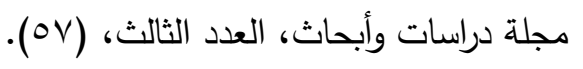

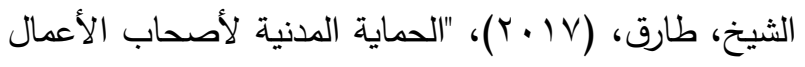

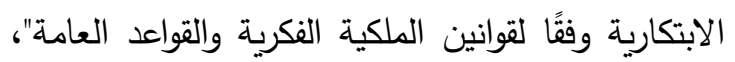

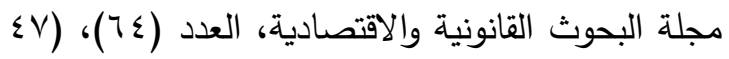

$$
\cdot(\varepsilon \wedge-
$$

الصبونجي، كريم، (V V • Y)،" حماية حقوق الملكية الفكرية بين الاتفاقيات الدولية والتشريعات العربية"، مجلة المهن

$$
\text { القانونية والقضائية، العدد الأول، (10). }
$$

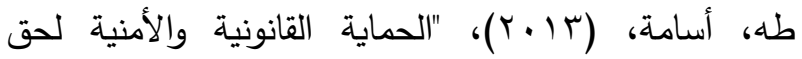
المؤلف"، مجلة مصر المعاصرة، العدد (9ه)، ( . . ؟).

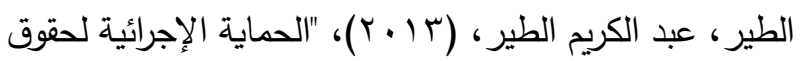

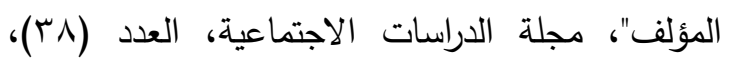

$$
\cdot(1 r \cdot-14 q)
$$

عباس، عبد الحميد، (Y (Y. (Y)، "حقوق المؤلف: طبيعتها

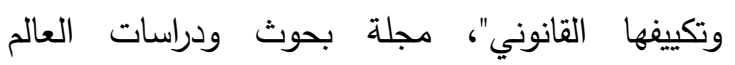

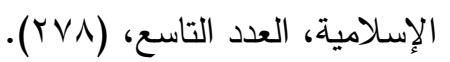

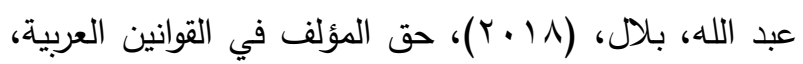
الطبعة الأولى، (لبنان: المركز العربي للبحوث القانونية

$$
\text { والقضائية)، ( • (r). }
$$

الخيكاني، ميري، (19 (Y)، "شروط مشروعية ممارسة

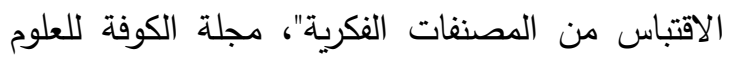

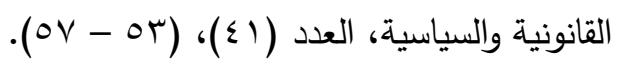

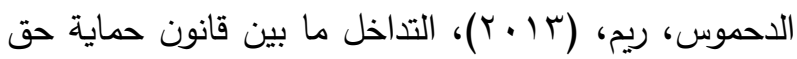
المؤلف وقانون الرسوم والنماذج الصناعية لحماية تصاميم الأزياء، رسالة ماجستير، (الأردن: جامعة آل

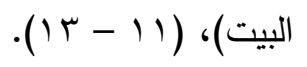

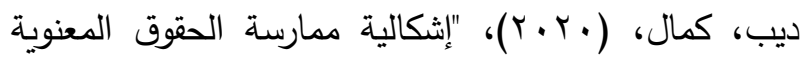
للمؤلف في البيئة الرقمية"، مجلة المشكاة في الاقتصاد - التمان التتمية والقانون، العدد الأول، (^r ( سالم، كريم، (Y • (Y)، "الحق في الصورة في التشريع العراقي: دراسة مقارنة مع التشريع المصري والفرنسي"، مجلة

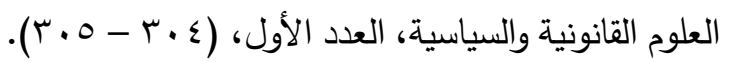

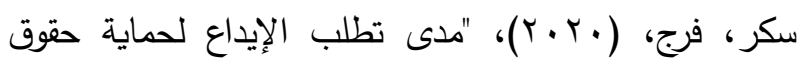
المؤلف"، مجلة الجامعة الإسلامية للدراسات الثرعية الثرات والقانونية: الجامعة الإسلامية بغزة، العدد الثاني، 9 .1. سعيد، سعودي، (ب (ب)، الأحكام المشتركة لعقود استغلال

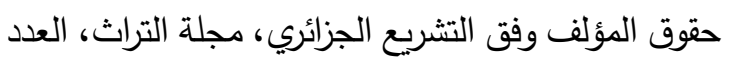
التاسع، ( • (V).

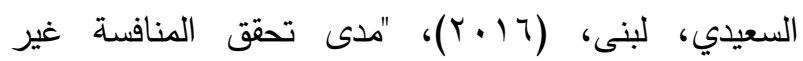
المشروعة في حق المؤلف"، المجلة المصرية للدراسات القانونية والاقتصادية، العدد السابع، (ب7 ؛ ).

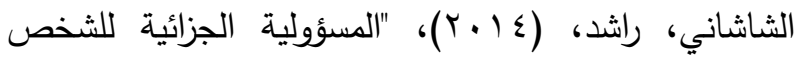

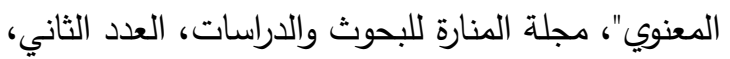

$$
\cdot(1 \vee \cdot-17 \Lambda)
$$

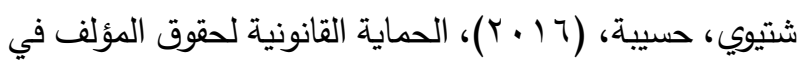
التشريع الجزائري، رسالة ماجستير، (الجزائر: جامعة

مرباح ورقلة)، (^). 


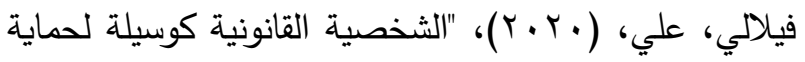

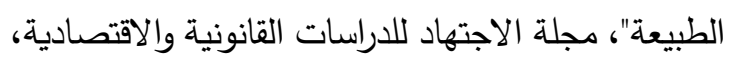

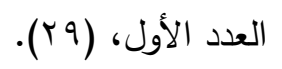

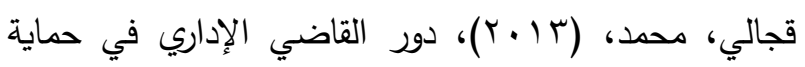

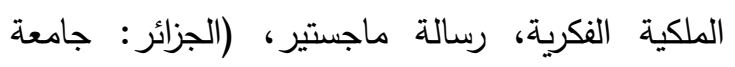

$$
\text { غليزان)، (1) (1). }
$$

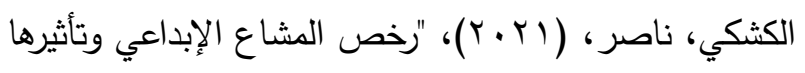

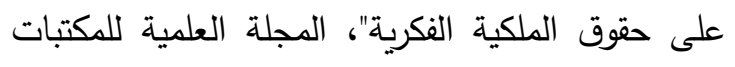

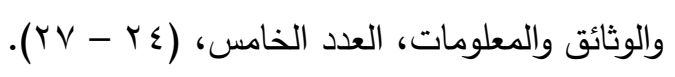

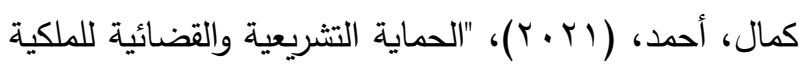

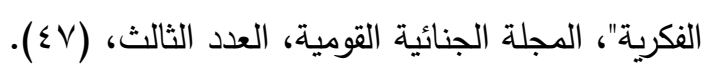

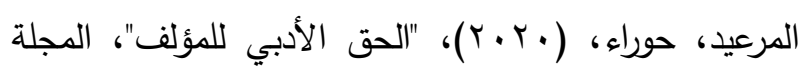

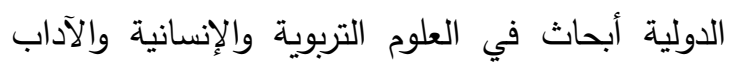

$$
\text { واللغات، العدد السادس، ( • V ( ). }
$$

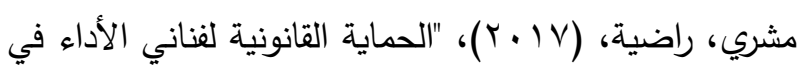

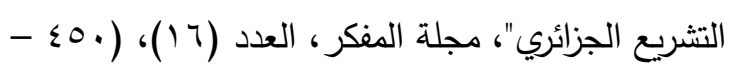

$$
\text { . ( } \leqslant 0)
$$

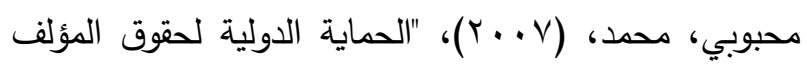
والحقوق المجاورة"، مجلة محاكمة، العدد الثاني، ( ع V ).

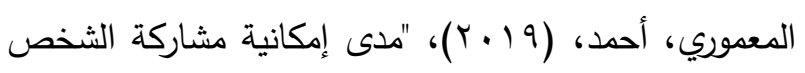

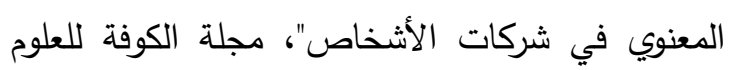

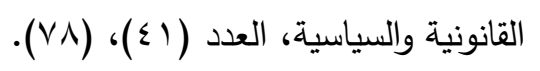

المغربي، طارق، (ع ( • Y)، "الاعتداء على المصنفات الأدبية

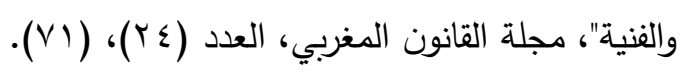

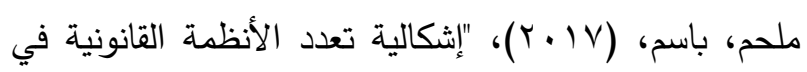

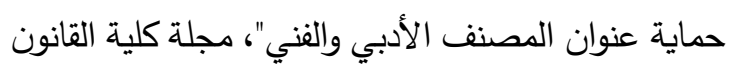

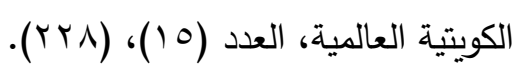

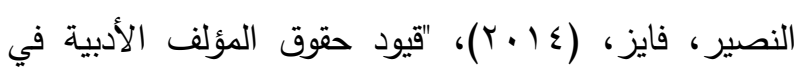
المصنفات الجماعية والعمالية"، مجلة الحقوق، العدد إنائ،

$$
\text { الثالث، ( ( }
$$

عبد الصادق، محمد، ( • · · )، "مستجدات الصياغة التشريعية لحقوق المؤلف والحقوق المجاورة في الكويت"، مجلة الحقوق، العدد الثاني، (101).

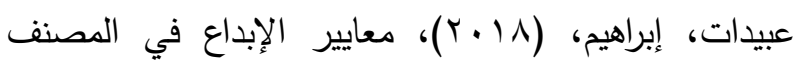

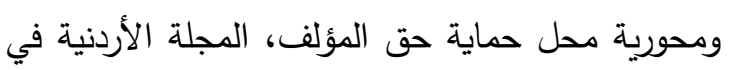
القانون والعلوم السياسية، العدد الأول، ( . . ب).

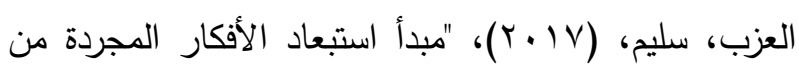
نطاق الحماية القانونية للملكية الفكرية"، مجلة البحوث

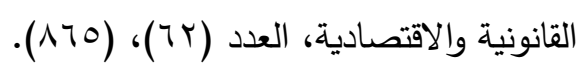

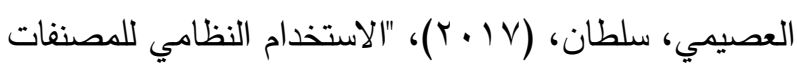

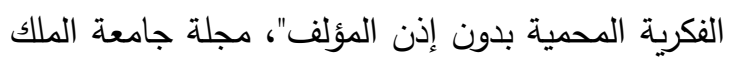
سعود - الحقوق والعلوم السياسية، العدد الأول، (9.1. (1)1-

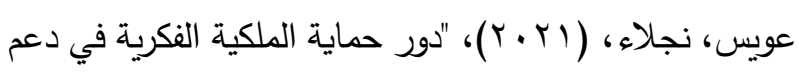
وتطوير البحث العلمي"، المجلة العلمية للمكتبات والوثائق

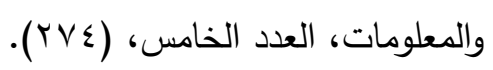

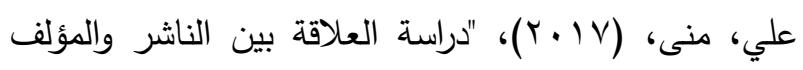

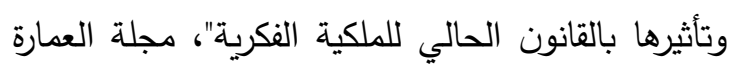
والفنون والعلوم الإنسانية، العدد الثامن، (ع ).

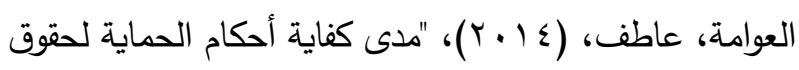

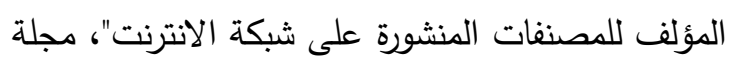

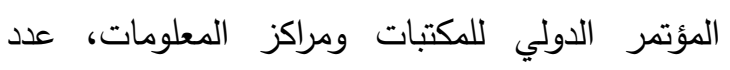

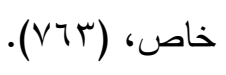

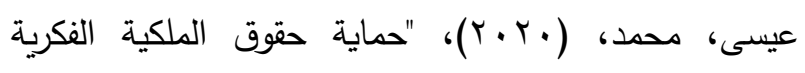

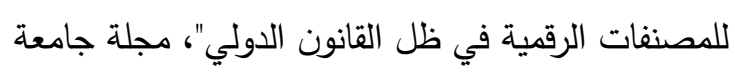
الملك عبد العزيز - الآداب والعلوم الإنسانية، العدد

$$
\text { السابع، ( • (V). }
$$

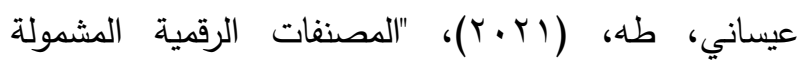
بالحماية بموجب قوانين الملكية الفكرية في الاتفاقيات

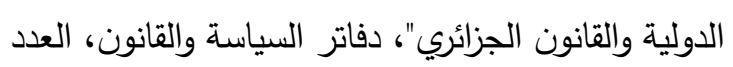

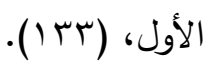




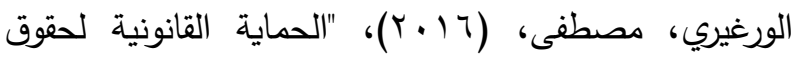
المؤلف في النطاق الرقمي"، منشورات المجلة المغربية

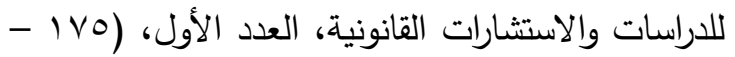
.$(1) 7$ يحيى، خديجة، (؟ ا ـ ب)، "النظام القانوني لمكافئة المؤلف في قانون الملكية الأدبية والفنية"، مجلة الفقه والقانون، العدد $\cdot(r, 0) ،(I V)$
الهندياني، خالد، (T ( • ب)، "الثيوع في حق المؤلف"، مجلة

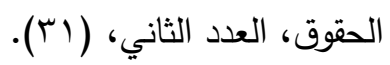

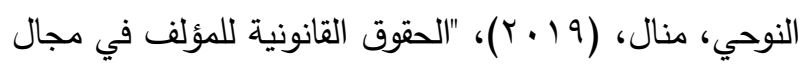

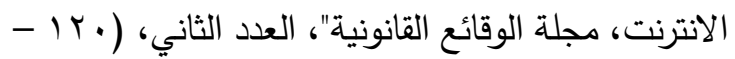
(I)

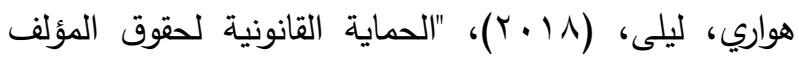
الأجنبي"، مجلة المؤتمر الدولي للمكتبات والمعلومات

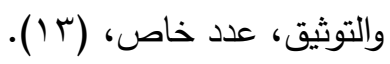




\title{
The Role of Innovation in Copyright
}

\author{
Maha Mukhlid Alotaibi \\ LLM student - Private Law \\ Faculty of Law - King Abdullaziz university - Saudi Arabia
}

Abstract. Intellectual property rights are an integral part of human rights. By believing in that importance, this study sought to demonstrate the legal value of innovation in copyright. This study analyzed the legal concept of copyright to determine the role of innovation into. As well this study reached some results, the most important is that innovation is the only condition for entitlement the legal protection. Because of that the legal protection must be without regard to any specifications, and without necessity of any procedures. 